\title{
Surface Electronic State Mediates Proton Transfer at Metal Nanoscale Interface for Catalytic Hydride Reduction of $-\mathrm{NO}_{2}$ to $-\mathrm{NH}_{2}$
}

\author{
Bing-Qian Shan, ${ }^{1}$ Jia-Feng Zhou, ${ }^{1}$ Meng Ding, ${ }^{1}$ Xiao-Dan Hu, ${ }^{1}$ Kun Zhang ${ }^{1,2,3 *}$ \\ ${ }^{1}$ Shanghai Key Laboratory of Green Chemistry and Chemical Processes, Laboratory of Interface and \\ Water Science, College of Chemistry and Molecular Engineering, East China Normal University, \\ Shanghai 200062, China; \\ ${ }^{2}$ Laboratoire de chimie, Ecole Normale Supérieure de Lyon, Institut de Chimie de Lyon, Université \\ de Lyon, 46 Allée d'italie, 69364 Lyon cedex 07, France; \\ ${ }^{3}$ Shandong Provincial Key Laboratory of Chemical Energy Storage and Novel Cell Technology, \\ School of Chemistry and Chemical Engineering, Liaocheng University, Liaocheng, 252059, \\ Shandong, P. R. China. \\ * Correspondence: kzhang@chem.ecnu.edu.cn (K.Z.)
}

\begin{abstract}
Concerted electron and proton transfer is a key step for the reversible conversion of molecular hydrogen in both heterogeneous nanocatalysis and metalloenzyme catalysis. However, its activation mechanism involving electron and proton transfer kinetics remains elusive. With the most widely used catalytic hydride reduction of 4-nitrophenol (4-NP) to 4-aminophenol (4-AP) as a model reaction, we evaluate the catalytic activity of noble metal NPs trapped in porous silica in aqueous $\mathrm{NaBH}_{4}$ solution. By virtue of a novel combination of catalyst design, reaction kinetics, isotope labeling, and multiple spectroscopic techniques, the real catalytic site for the conversion of $-\mathrm{NO}_{2}$ to $-\mathrm{NH}_{2}$ is identified to be the water-hydroxyl transition metal complex, which could further react with $\mathrm{NaBH}_{4}$ to form a new triangular configuration metal complex of $\mathrm{H}_{3} \mathrm{~B}$-water-hydroxyl with dynamic feature. It yields an ensemble of surface electronic states (SESs) though space overlapping of $p$ orbitals of one $B$ and several $O$ atoms (including the $O$ atoms of 4-NP), which could act as an alternative channel for concerted electron and proton transfer. This work highlights the critical role of conceptual SESs model in heterogeneous catalysis to tune the chemical reactivity and also sheds light on the intricate working of the $[\mathrm{FeFe}]$-hydrogenases.
\end{abstract}

\section{Introduction}

The "pool of electrons" present on metal NPs surface has been extensively used to drive a wide range of chemical transformations (1-6). Among of them, the hydride reduction of 4-NP to 4- AP in an aqueous solution using sodium borohydride $\left(\mathrm{NaBH}_{4}\right)$ as a hydride source is the one of the most widely used model reaction to evaluate the catalytic activity of a large variety of metal NPs catalyst (7-13). It is generally believed that, the metal NPs is the active site of catalytic hydride reduction, which offers a dual role by providing its surface for the adsorption of reactants and mediating the transfer of electrons and protons 
to reduce the kinetic barrier for the $-\mathrm{NO}_{2}$ to $-\mathrm{NH}_{2}$ conversion $\left(\mathrm{NaBH}_{4}\right.$ reducer is taken for granted as the source of hydrogen, Scheme 1a). However, the mass of solid evidences showed that, the efficiency of the catalytic 4-NP to 4-AP conversion is not only attributed to the metal NPs centers $(14,15)$, but also to the microenvironment of the secondary coordination sphere of metal center, such as the $\mathrm{pH}$ and the type of solvent (16-23), Very interestingly, the deuterium isotopic experiments recently confirmed that the interface water is prerequisite for catalytic reduction, and that, counter-intuitively, it is water rather than the $\mathrm{NaBH}_{4}$ reducer that provides the hydrogen for the formation of the 4-AP product $(16,24)$, suggesting a completely new water-mediated proton transport mechanisms for the catalytic hydride reduction of $-\mathrm{NO}_{2}$ to $-\mathrm{NH}_{2}$ at metal NPs surface.

(a)

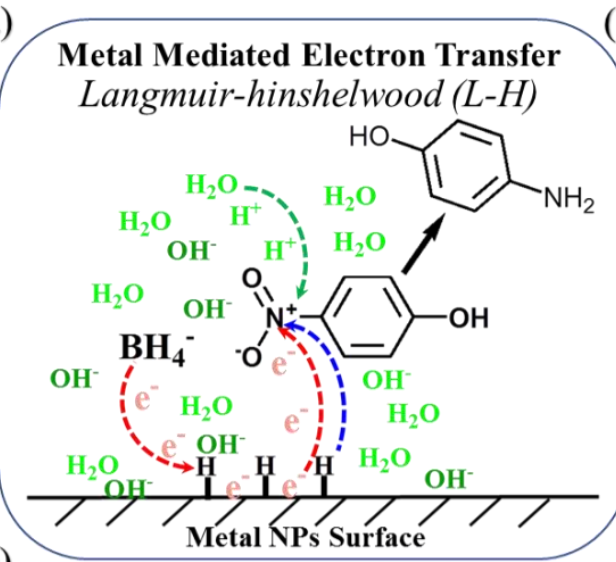

(c)

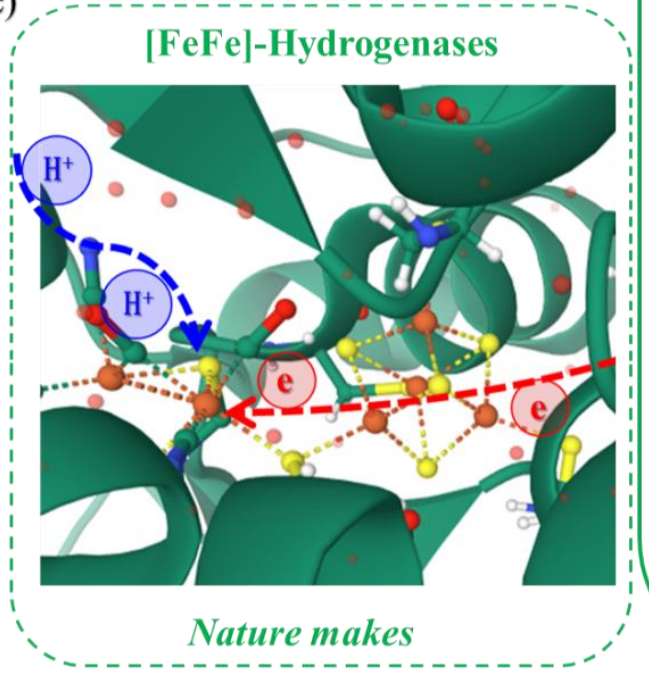

(b)

Surface Electronic States (SESs) Mediated Proton Transfer

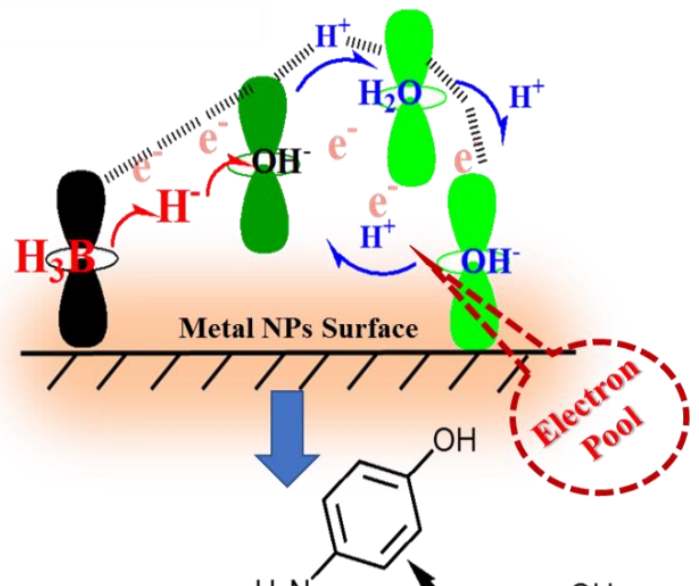

Scheme 1 Comparison of different reaction mechanisms in metal catalyzed hydride reduction of 4-nitrophenol (4-NP) in aqueous $\mathrm{NaBH}_{4}$ solution. (a) Metal mediated electron transfer Langmuir-Hinshelwood (LH) mechanism, (b) Our proposed surface electronic states (SRSs) dependent proton transfer mechanism, and (c) A coupled mechanism for proton and electron transport to the active site though an activated water channel in [Fe-Fe]-hydrogenases.

In this report, with mesoporous silica nanosphere (MSNs) supported noble metal NPs as a model catalyst, we systematically study the effects of different 
reaction parameters on the reduction kinetics in the aqueous $\mathrm{NaBH}_{4}$ solution, mainly including the composition and valence of metals $(\mathrm{Ag} / \mathrm{Pd} / \mathrm{Pt})$, isotopic solvent $\left(\mathrm{D}_{2} \mathrm{O}\right)$ or reducer $\left(\mathrm{NaBD}_{4}\right)$, and concentration of sodium hydroxide $(\mathrm{NaOH})$. The reaction rate is strongly dependent on the composition of metals and isotope effect of solvent and reducer. But surprisingly, Fourier transform infrared (FTIR) and isotope labeling experiments evidence that the hydrogen in the final product 4-AP comes from water solvent, instead of the reducer $\left(\mathrm{NaBH}_{4}\right)$, independent on the metal nature of catalytic site. A thorough investigation by optical spectrum and ${ }^{1} \mathrm{H}$ nuclear magnetic resonance (NMR) spectroscopies reveals that the hydride reduction of 4-NP at nanoscale interface proceeds by a new metal surface intermediate of $\mathrm{H}_{3} \mathrm{~B}$-water-hydroxyl with triangular configuration (Scheme 1b). If the $\mathrm{O}$ atoms of reactant 4-NP are involved, a four-center activated surface complex $\mathrm{H}_{3} \mathrm{~B}$-water-hydroxyl-4-NP should be considered, which could be surrounded by $\mathrm{H}$-bonding water molecules (Scheme 1b). This unique multicenter intermediate yield an ensemble of surface electronic states (SESs) though space overlapping of $p$ orbitals of $\mathrm{B}$ and $\mathrm{O}$ atoms, which could act as a reaction channel to promote concerted electron and proton transfer by Grotthus hopping mechanism (25-32). This new electronic state dependent proton transport dynamic was only recently observed in [FeFe]-hydrogenases for proton reduction (Scheme 1c) (33-42).

\section{Results and Discussions}

The most commonly used Pt/Pd /Ag NPs were trapped into the mesopores of dendritic mesoporous silica nanospheres (DMSNs) as model catalysts for mechanistic study of hydride reduction of $-\mathrm{NO}_{2}$ to $-\mathrm{NH}_{2}$. The fabrication of $\mathrm{Ag}$ NPs based catalyst could be a typical example, where highly dispersed Ag NPs with a narrow particle size distribution of ca. $2.0 \mathrm{~nm}$ were obtained due to the unique nanopore confinement effect of DMSNs (Synthetic details provided in the Supporting Information, $(19,43-45)$. Figure 1a shows that the reaction rate of hydride reduction of 4-NP to 4-AP is strongly dependent on the metal type of catalysts in an order of $\mathrm{Ag}\left(0.57 \mathrm{~min}^{-1}\right)>\mathrm{Pd}\left(0.52 \mathrm{~min}^{-1}\right)>\mathrm{Pt}(0.06$ $\left.\mathrm{min}^{-1}\right)$. At identical reaction conditions, $\mathrm{Ag}$ and $\mathrm{Pd}$ NPs catalysts show the similar reaction activity. However, unexpectedly, Pt NPs exhibits the lowest reaction rate since it is the one of best metal catalysts to activate the reducing agent $\mathrm{NaBH}_{4}$ with the formation of stabilized platinum hydride surface species, suggesting that the $\mathrm{B}-\mathrm{H}$ bond cleavage in $\mathrm{NaBH}_{4}$ reducer is not the rate-determining step for catalytic hydride reduction of 4-NP. 

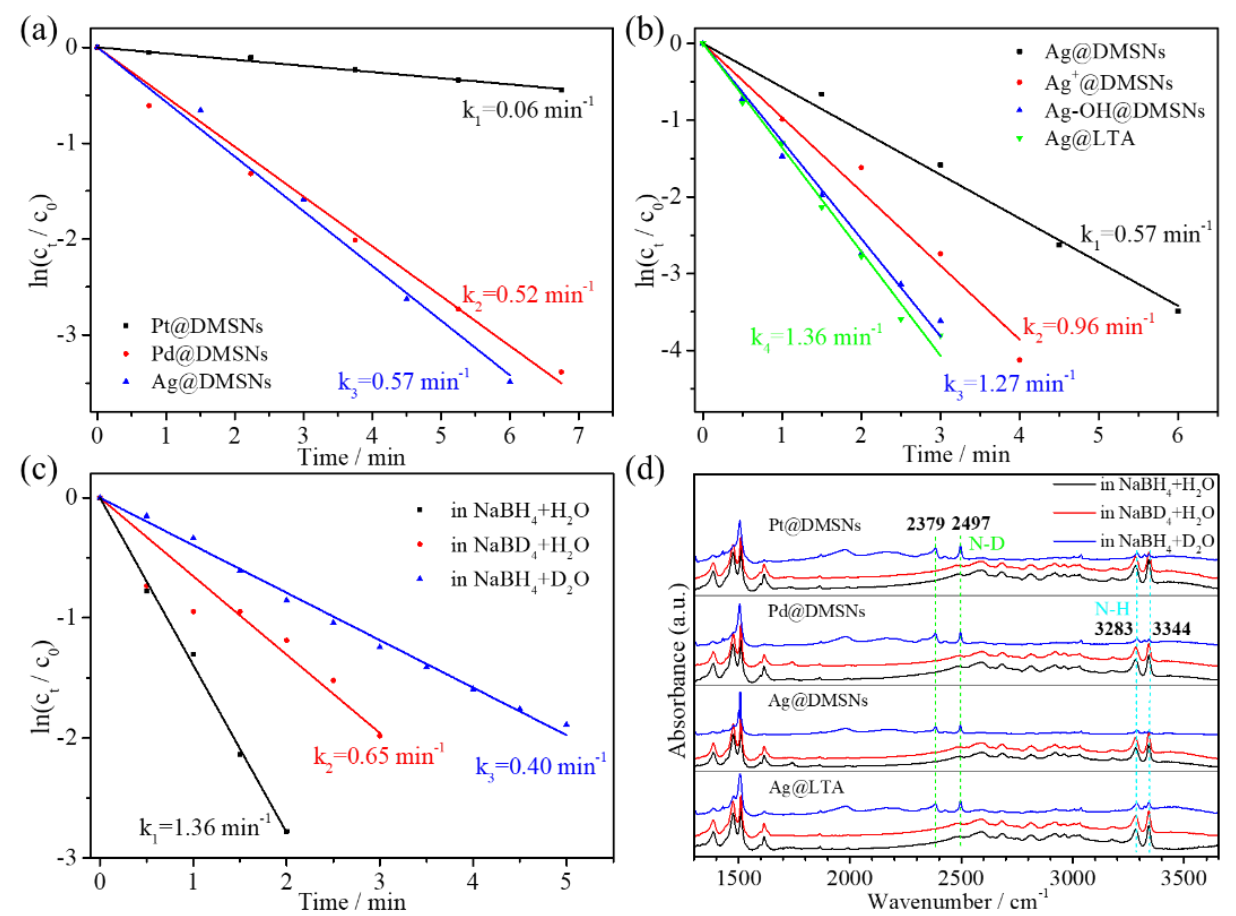

Figure 1. Kinetic data of the catalytic hydride reduction of 4-NP, (a) Metal type effects of $\mathrm{Pt} / \mathrm{Pd} / \mathrm{Ag}$ NPs supported catalysts, (b) Microenvironment effects of Ag NPs supported catalysts, (c) Kinetic isotope effects (KIEs) of $\mathrm{NaBD}_{4}$ or $\mathrm{D}_{2} \mathrm{O}$, and, (d) FTIR spectra of the final products after the hydride reduction of 4-NP using $\mathrm{NaBH}_{4}$ and $\mathrm{H}_{2} \mathrm{O}$ (black line), $\mathrm{NaBD}_{4}$ and $\mathrm{H}_{2} \mathrm{O}$ (red line), and $\mathrm{NaBH}_{4}$ and $\mathrm{D}_{2} \mathrm{O}$ (blue line).

In addition, we interestingly found that not only the metal type, but also the delicate change of microenvironments of the same metal center (Ag NPs) significantly affected the reaction kinetics (Figure 1b), such as the valence state of $\mathrm{Ag}$ atoms and the pre-adsorption of hydroxide on the Ag NPs, which was never reported before. To our surprises, Ag+@DMSNs catalyst without the last step of metal reduction showed better catalytic performance $\left(\mathrm{k}_{2}=0.96\right.$ $\left.\mathrm{min}^{-1}\right)$, compared to Ag NPs catalysts with zero valence charge $\left(\mathrm{k}_{1}=0.57\right.$ $\mathrm{min}^{-1}$ ), indicating that metal surface is not necessary for interfacial electron transfer, in other words, the electrons could be transported by other pathway. However, some ones may doubt this conclusion owing to the self-reduction of $\mathrm{Ag}^{+}$to $\mathrm{Ag} \mathrm{NPs}$ in the ambient conditions since ca. $17.0 \%$ of zero valence $\mathrm{Ag}$ atoms were observed in this sample by XPS measurement (Fig. S2 and Table S1). To preclude this possibility, a completely $\mathrm{Ag}^{+}$cation exchanged LTA zeolite catalyst was sophisticatedly designed, it even shows superior catalytic performance $\left(\mathrm{k}_{4}=1.36 \mathrm{~min}^{-1}\right)$ over $\mathrm{Ag}^{+} @ \mathrm{DMSNs}\left(\mathrm{k}_{2}=0.96 \mathrm{~min}^{-1}\right)$, surpassing all the reported Ag NPs catalysts (Table S2). This diagnostic experiment further confirms that the metal NPs mediated electron transfer process is not main reaction channel for hydride reduction of 4-NP to 4-AP (Scheme 1a), which also answers the abnormal catalytic behavior of Pt NPs catalyst with ultra-low catalytic reactivity (Figure 1 a). Instead, we observed that the delicate change of microenvironment of metal active sites, for example, the introduction 
of hydroxide groups $\left(\mathrm{OH}^{-}\right)$with proper adsorbed amount on metal centers during the preparation of catalysts significantly accelerates the rate of hydride reduction of 4-NP up to $1.27 \mathrm{~min}^{-1}$ (Figure $1 \mathrm{~b}$, blue line). However, if more $\mathrm{OH}^{-}$ was adsorbed on the active sites, the reaction was inhibited (Fig. S3). Similar results were recently reported (17). This suggests that, hydroxide groups involves the fabrication of surface active site, and mediates the proton transfer in the reduction of 4-NP to 4-AP as a key reaction step under the help of surrounding water molecules.

Kinetic isotope effects (KIEs) with deuterated reducing agent $\mathrm{NaBD}_{4}$ and/or solvent $\mathrm{D}_{2} \mathrm{O}$ was used to further elucidate the mechanisms of reactions and determine the bond-breaking positions and the rate-determining steps (RDS). The results of reaction kinetics are shown in Figure 1c, and all the reactions follow pseudo-first-order kinetics (46). The reagent ( $\left.\mathrm{kNaBH}_{4} / \mathrm{NaBD}_{4}\right)$ and solvent $\left(\mathrm{H}_{2} \mathrm{O} / \mathrm{D}_{2} \mathrm{O}\right) \mathrm{KIEs}$ value is 2.09 and 3.40 (Figure 1c), respectively, which indicates that the dissociation of the $\mathrm{B}-\mathrm{H}$ bond of borohydride ions and $\mathrm{O}-\mathrm{H}$ bond of water solvent both involve the reaction kinetics of catalytic hydride reduction of 4-NP $(47,48)$. The larger KIEs value of solvent water $(3.40)$ over reducing agent $\mathrm{NaBH}_{4}$ (2.09) found here demonstrate that the combination of a nitro group with protons in the solvent $\mathrm{H}_{2} \mathrm{O}$ is the RDS of this reaction.

Besides the kinetic investigations, the FT-IR spectroscopic analysis of the final products after deuterium isotopic experiments also provide direct experimental evidences to understand the hydride reduction mechanics (Figure 1d). When reduction occurs in an aqueous solution of $\mathrm{NaBH}_{4}$, the absorbance peaks at approximately 3283 and $3344 \mathrm{~cm}^{-1}$ are attributed to the $\mathrm{N}-\mathrm{H}$ bond (Figure 1d, black line) $(16,20)$, indicating the formation of products 4-AP in agreement with that of commercial 4-AP (Figure S5). However, when the deuterated reducer $\mathrm{NaBD}_{4}$ is used, counter-intuitively, the hydrogen atoms of $-\mathrm{NH}_{2}$ are not from $\mathrm{BH}_{4}{ }^{-}$because of the absence of $\mathrm{N}-\mathrm{D}$ stretching vibrations (Figure 1d, red line). To our surprises, when $\mathrm{D}_{2} \mathrm{O}$ is introduced, two fingerprint $\mathrm{N}-\mathrm{D}$ stretching bands of 4-AP at 2379 and $2497 \mathrm{~cm}^{-1}$ are observed (16), concomitantly, accompanying a decrease of adsorption intensity of $\mathrm{N}-\mathrm{H}$ vibration in a range of $3200-3400 \mathrm{~cm}^{-1}$ (Figure $1 \mathrm{~d}$, blue line). The key role of water as proton donors for the conversion of 4-NP is also proved. When the other solvents are used, such as ethanol (EtOH) and tetrahydrofuran (THF), the reduction of 4-NP can hardly happen (Fig. S6), consistent with recently reported results $(16,20)$. It is importantly noted that, this finding is not only limited to the Ag NPs based catalyst, but also for Pd and Pt NPs catalysts. Thus, taken all results together, we confirm that the $\mathrm{H}$ atoms are from the protic solvent water, instead of hydride reducer $\mathrm{NaBH}_{4}$, suggesting a completely new surface electronic states (SESs) dependent proton transfer mechanism to tune the hydride reduction of $-\mathrm{NO}_{2}$ to $-\mathrm{NH}_{2}$ at metal naoscale interface (Scheme 1a and 1c). 

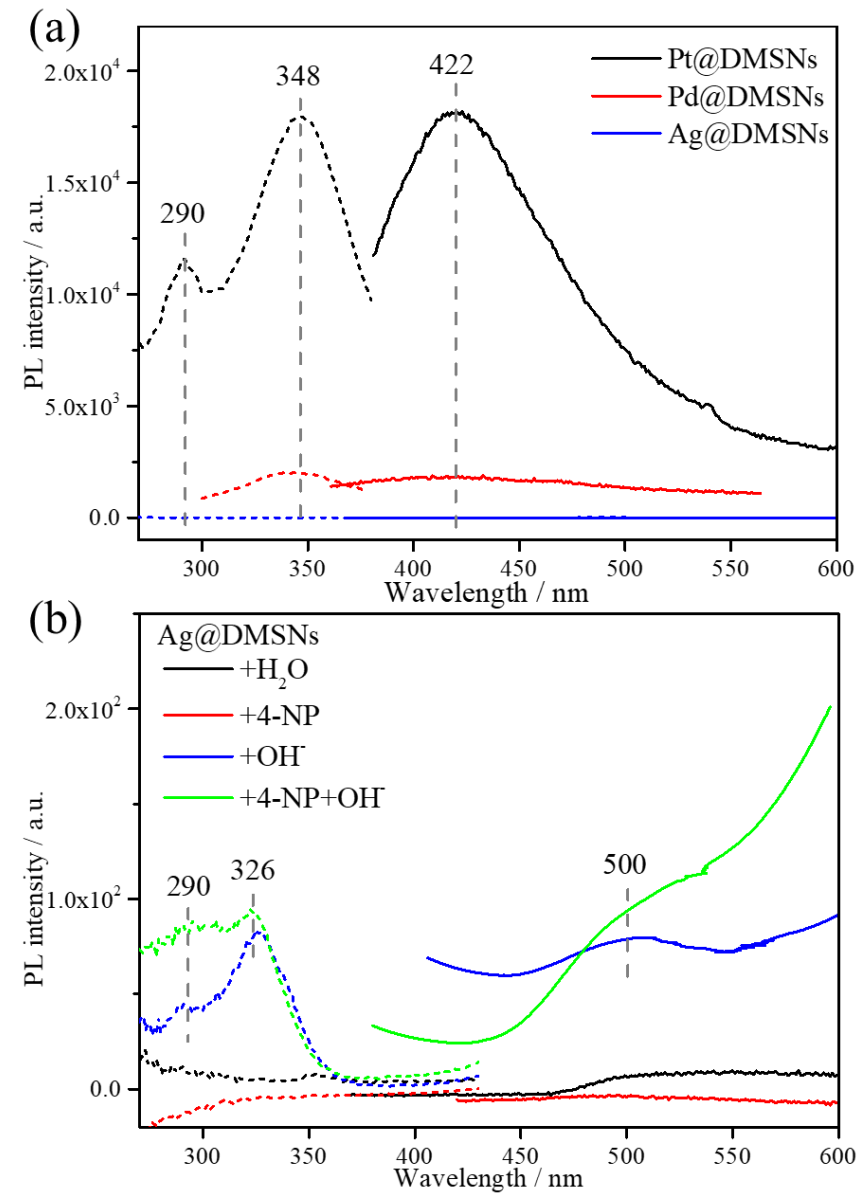

Figure 2. Excitation (dash line) and emission spectra (solid line) of Pt, Pd and Ag NPs supported DMSNs catalysts (a), and Ag NPs supported DMSNs catalysts with modified catalytic active sites (b).

Optical spectroscopy is a powerful characterization tool to determine the nature of surface electron states (SESs).Very recently, on the surface of metal nanoclusters (NCs) core, some $\mathrm{p}$ band intermediate states (PBISs) were captured by a steady and ultrafast transient absorption spectrum, which is formed through space interactions of $p$ orbitals of paired $O$ atoms in the hydrated hydroxide complexes; and upon photoexcitation, the brighter tunable photoluminescence (PL) emissions from these transient states (PBISs) were observed with the characteristic of a $\Pi \rightarrow \pi^{*}$ transition (49-52). Due to the similarity in preparations for $\mathrm{Pt} / \mathrm{Pd} / \mathrm{Ag} \mathrm{NPs}$ catalysts and metal NCs, the identical SESs on Metal NPs surface should be formed, which could act as alternative reaction channels for the high-rate reduction of 4-NP by a concerted electron and proton transfer dynamics, as a reminiscent of [FeFe]-hydrogenase mechanism (Scheme $1 \mathrm{~b}$ and 1c) (39-42). Figure 2 shows the excitation and photoemission spectra of Pt/Pd/Ag NPs supported DMSNs catalysts. When these catalysts are directly dispersed into water solution, $\mathrm{Pt}$ NPs based catalyst emits the strongest fluorescence at $430 \mathrm{~nm}$ with an excitation band at ca. $348 \mathrm{~nm}$, which is followed by Pd and Ag NPs catalysts 
(Figure 2a), indicating the most stable luminous centers on the Pt NPs surface. We interestingly observe that, the reaction rate of 4-NP reduction is inversely proportional to the stability of the luminescent center, and that Ag NPs based catalyst exhibits the best catalytic performance in the conversion of 4-NP to 4-AP (Figure 1a). This is probably due to the strong coordination between $\mathrm{Pt}$ and surface $\mathrm{OH}$ species, which prohibits the chemical adsorptions of reducer $\mathrm{NaBH}_{4}$ and reactant 4-NP, consequently resulting in the lower reactivity (53, 54).

Linking to the data of reaction kinetics (Figure 1b), the chemical reactivity of Ag NPs based catalysts not only depends on the stability of SESs, but also its density. Owing to the relative weak coordination ability between $\mathrm{Ag}^{+}$and hydroxide group, at metal surface, reactant 4-NP could compete for the adsorption of hydroxide groups. The observation of excitation and emission spectrum prove this point. When the weak luminescent Ag NPs based catalysts were dispersed into the mixed $\mathrm{H}_{2} \mathrm{O} / \mathrm{NaOH}$, distinct luminescence emissions at ca. $500 \mathrm{~nm}$ were observed due to the formation of more surface metal complexes in a formula of $\left[\mathrm{Ag}^{+} \cdot\left(\mathrm{OH}^{-} \cdot \mathrm{H}_{2} \mathrm{O}\right)\left(\mathrm{H}_{2} \mathrm{O}\right)_{n-1}\right]$ (Figure $2 \mathrm{~b}$ and Scheme 1c). When the catalysts are added into the mixed 4-NP/NaOH solution, the PL at ca. $500 \mathrm{~nm}$ is more intensified, and concomitantly with a significant increase of excitation band absorption at ca. $290 \mathrm{~nm}$ (Figure 2b, green line), which indicates the switching of the surface complex from $\left[\mathrm{Ag}^{+} \cdot\left(\mathrm{OH}^{-} \cdot \mathrm{H}_{2} \mathrm{O}\right)\left(\mathrm{H}_{2} \mathrm{O}\right)_{\mathrm{n}-1}\right]$ to $\left[\mathrm{Ag}^{+} \cdot\left(\mathrm{OH}^{-} \cdot 4-\mathrm{NP}\right)\left(\mathrm{H}_{2} \mathrm{O}\right)_{\mathrm{n}-1}\right]$. Obviously, the change of optical properties is caused by the structural discrepancy of two intermediate states, suggesting the varied overlapping of the two $p$ orbitals of $\mathrm{O}$ atoms from hydroxide groups and /or 4-NP (49). This finally determines the reaction kinetic of 4-NP reduction. In a word, SESs formed by surface ligated complex provide an alternative pathway for interfacial electron transfer, differing from the mode of well-recognized metal-surface mediated electron transfer dynamics (54-56). 

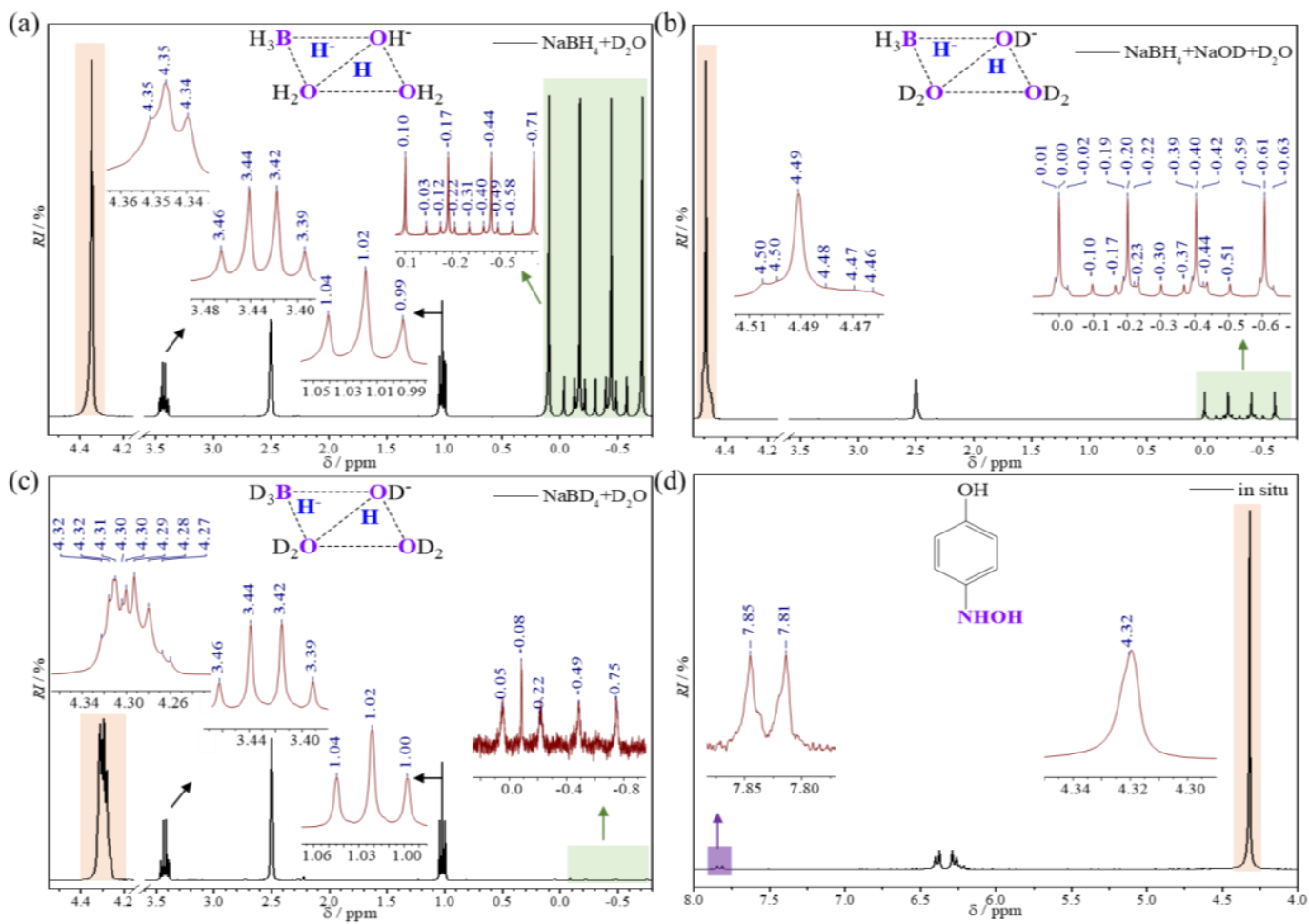

Figure 3. ${ }^{1} \mathrm{H}$ NMR spectra to probe the intermediate species and the reaction mechanism of Ag NPs catalyzed hydride reduction of 4-NP during the in-situ and ex-situ reaction with different combinations of $\mathrm{NaBH}_{4}$ and $\mathrm{D}_{2} \mathrm{O}$ (a); $\mathrm{NaBH}_{4}, \mathrm{NaOD}$ and $\mathrm{D}_{2} \mathrm{O}$ (b); $\mathrm{NaBD}_{4}$ and $\mathrm{D}_{2} \mathrm{O}$ (c) and $\mathrm{Ag} @ D M S N s$ catalyst, 4-NP, $\mathrm{NaBH}_{4}$ and $\mathrm{H}_{2} \mathrm{O}$ (d).

The optical spectrum proves the presence of SESs as a reaction channel for electron transfer, but it cannot give any detailed information on the critical step of $\mathrm{H}^{-}$transfer from $\mathrm{NaBH}_{4}$ to $\mathrm{H}_{2} \mathrm{O}$ via SESs. The systematically designed ${ }^{1} \mathrm{H}$ NMR spectroscopies can identify these intermediate species formed during in-situ and ex-situ reactions with deuterated chemical agents of $\mathrm{NaBD}_{4}, \mathrm{NaOD}$ and $\mathrm{D}_{2} \mathrm{O}$, especially the delicate change of the hydrogen local environments in $\mathrm{NaBH}_{4}$ and $\mathrm{H}_{2} \mathrm{O}$ molecules. At this point, it is importantly noted that, to improve the resolution of ${ }^{1} \mathrm{H}$ NMR data permitting the clear observation of intermediate species with narrow multiplets, and, in addition to avoiding the peak broadening of freely tumbling $\mathrm{H}_{2} \mathrm{O}$ on the signal, no external water is extra-added, since the source of $\mathrm{H}_{2} \mathrm{O}$ only through absorption of $\mathrm{H}_{2} \mathrm{O}$ in the air into the $\mathrm{D}_{2} \mathrm{O}$ solvent is enough to collect the information of hydrogen local environments (57).

Depending on the presence or absence of $\mathrm{NaOH}$ or $\mathrm{NaOD},{ }^{1} \mathrm{H}$ NMR spectra in Figure 3 shows two typical characteristics with high resoluted multiplets. In the absence of $\mathrm{NaOH}$ or $\mathrm{NaOD}$, the ${ }^{1} \mathrm{H}$ spectrum of $\mathrm{NaBH}_{4}$ alone is composed of four components (Figure 3a, $3 \mathrm{c}$ and Fig. S7, 8): one resonance centered at $-0.3 \mathrm{ppm}$ with four peaks from $\mathrm{NaBH}_{4}$, one at ca. $4.3 \mathrm{ppm}$ from $\mathrm{H}_{2} \mathrm{O} / \mathrm{OH}$ hydrogen-bonded to $\mathrm{NaBH}_{4}$, and the other two resonances at ca. 3.43 and $1.02 \mathrm{ppm}$, which are unprecedentedly assigned. However, when $\mathrm{NaOH}$ or $\mathrm{NaOD}$ introduced, these two resonances are completely disappeared (Figure 
$3 \mathrm{~b}$ and Fig, S9, 10), suggesting two different type of hydrogen with proton characteristic, likely to be intermediate species from hydride of $\mathrm{NaBH}_{4}$ and proton of $\mathrm{H}_{2} \mathrm{O}$ due to the $\mathrm{H}^{-}$electron transfer from $\mathrm{NaBH}_{4}$ to $\mathrm{H}_{2} \mathrm{O}$ via SESs. These assignments also answer why they are the quartet and triplet splitting (Figure 1a) with their own characteristic of topology bond of $\mathrm{NaBH}_{4}$ and $\mathrm{H}_{2} \mathrm{O}$, indicating the electrons were captured into the unique quantum confinement space, here we called it the "pool or sea of electrons". This is also consistent with the observations that the hydrogen resource of 4-AP is originated from the water solvent, instead of $\mathrm{NaBH}_{4}$ reducer (Figure 1c and 1d).

The close examination of ${ }^{1} \mathrm{H}$ spectrum at resonances of 4.3 and $-0.3 \mathrm{ppm}$ can give more structural information of intermediate species (Figure $3 \mathrm{a}, 3 \mathrm{~b}$ and 3c). Generally, the broad resonance of freely tumbling $\mathrm{H}_{2} \mathrm{O}$ is assigned to ca. $4.6 \mathrm{ppm}$ (57), however, here, an upper-field shift narrow peak centered at 4.3 $\mathrm{ppm}$ with high resoluted multiplets is observed probably due to the shielding effect as a result of increased electron density between the hydrogen-bonded protons in the sea of electrons, especially when deuterated reducing agent $\mathrm{NaOD}$ and/or $\mathrm{NaBD}_{4}$ used (Figure $3 \mathrm{~b}$ and $3 \mathrm{c}$ ), suggests a very short distance between protons from $\mathrm{H}_{2} \mathrm{O} / \mathrm{NaOH}$ and those from $\mathrm{NaBH}_{4}, \sim 1.8 \AA(58,59)$. The introduction of $\mathrm{NaOD} / \mathrm{D}_{2} \mathrm{O}$ to $\mathrm{NaBH}_{4}$ allows isotopic tumbling of the $\mathrm{BH}_{4}{ }^{-}$ ions, which averages out ${ }^{1} \mathrm{H}-{ }^{1} \mathrm{H}$ homonuclear dipolar coupling and yields narrower resonances with significantly improved resolution, which permits the observation of multiplets due to relatively weak J-coupling interactions on the order of $\mathrm{Hz}$ (57). In the ${ }^{1} \mathrm{H}$ NMR of the $\mathrm{NaBH}_{4}+\mathrm{D}_{2} \mathrm{O}$ sample, the $\mathrm{NaBH}_{4}$ resonance first splits into four peaks with a J-coupling spacing of $81 \mathrm{~Hz}$ from through-bond interactions of ${ }^{1} \mathrm{H}$ and ${ }^{11} \mathrm{~B}$. Then each of the four peaks further splits into 2 with a spacing of $27 \mathrm{~Hz}$ (Figure 1a and 1b, in green shadow), which is due to the J-coupling between protons from $\mathrm{H}_{2} \mathrm{O}$ and $\mathrm{NaBH}_{4}$ via hydrogen bonds. The relatively large $\mathrm{J}$-coupling interactions of $81 \mathrm{~Hz}$ between $\mathrm{H}_{2} \mathrm{O}$ and $\mathrm{NaBH}_{4}$ further suggests a short interaction distance between water (or $\mathrm{NaOH}$ ) and $\mathrm{NaBH}_{4}$ in $\mathrm{H}_{3} \mathrm{~B}$-water-hydroxyl complex with a dynamic triangular configuration (as illustrated in the cartoons of Figure 3 and Scheme 1b), which shows an ultrafast dynamic behavior with a rapid switching between $\mathrm{B}-\mathrm{O}$ and $\mathrm{O}-\mathrm{O}$ chemical bonds in triangular configurations, like 2-norbornyl cation (One of the most famous carbonium cations) with non-classical structure featured with well delocalized bonding interactions (three-center, two-electron (3c-2e) bond among C1, C2 and C6 atoms) (60, $61)$.

The precise composition of this unique complex also can be deduced based on the area integral of ${ }^{1} \mathrm{H}$ spectrum of $\mathrm{NaBH}_{4}+\mathrm{D}_{2} \mathrm{O}$ sample at resonances of 4.3, 3.43, $1.02 \mathrm{ppm}$ in a ratio of 3.5: 0.8: 1.2 (Figure 3a), which accounts for one of water dimer, one quasi-hydride from $\mathrm{NaBH}_{4}$ and one of quasi-proton from water. The presence of quasi-hydride and proton is attributed to the key step $\mathrm{H}^{-}$electron transfer for 4-NP reduction. In addition, the sum of area 
integral of these two quasi- hydrogen atoms $(3.08+4.43=7.51)$ is in surprising consistence with the total area of multiplets centered at -0.31 (with a $\mathrm{J}$ spacing of $27 \mathrm{~Hz}, 1.00+1.18+1.14+0.98+1.21+1.07+1.03=7.51)$, indicating the fate of multi-peaks splitting due to the $\mathrm{J}$-coupling between protons from $\mathrm{H}_{2} \mathrm{O}$ and $\mathrm{NaBH}_{4}$ via hydrogen bonds (Figure 3a). This structure is further confirmed by the addition of $\mathrm{NaOD}$ in figure $3 \mathrm{~b}$ : two new quartet splitting peaks are easily distinguished, which are located on both sides of the center of $\mathrm{NaBH}_{4}$ quartet peak at $-0.3 \mathrm{ppm}$. The formation of these quartet splitting peaks are attributed to a strong $\mathrm{J}$-coupling interactions via through-bond interactions of ${ }^{1} \mathrm{H}$ and ${ }^{16} \mathrm{OH}_{2}$ and ${ }^{1} \mathrm{H}$ and ${ }^{2} \mathrm{DO}^{-}$in the $\mathrm{H}_{3} \mathrm{~B}$-water-hydroxyl complex, respectively. Finally, ${ }^{1} \mathrm{H}$ NMR of $\mathrm{NaBH}_{4}+\mathrm{H}_{2} \mathrm{O}+4-\mathrm{NP}$ sample in Figure $3 \mathrm{~d}$ during the hydride reduction captures the intermediate hydroxylamine specie with typical doublet resonances at 7.85 and $7.81 \mathrm{ppm}$, indicating the hydride reduction of 4-NP is via the direct hydroxylamine route, instead of indirect condensation route of azoxy compounds $(7,16,24)$.

\section{Conclusions}

The results of optical and ${ }^{1} \mathrm{H}$ NMR spectroscopies together with the reaction kinetic data and isotope labeling experiment of $\mathrm{NaBD}_{4}$ and $\mathrm{D}_{2} \mathrm{O}$ evidence that the catalytic hydride reduction of 4-NP on metal NPs surface follows a completely new reaction pathway, i.e., the surface electronic states (SESs) dependent proton transfer dynamics (Scheme 1b). $\mathrm{BH}_{4}^{-}$is electrostatically interacts with metal NPs and reacts with pre-adsorbed structural water molecules $\left(\mathrm{H}_{2} \mathrm{O} \cdot \mathrm{OH}^{-}\right)$to form a triangular configuration complex of $\mathrm{H}_{3} \mathrm{~B}$-water-hydroxyl by spatial overlapping of $\mathrm{p}$ orbitals of $\mathrm{B}$ and $\mathrm{O}$ atoms in Van der Waals radius, which induces the formation of dynamic SESs. Importantly note that, the fabrication of SESs is not only limited to $B$ and $O$, but also it can also be extended to other heteroatoms, such as $C, N, S, P$ etc. These unique SESs provide an alternative reaction channel for $\mathrm{H}^{-}$electron transfer to metal surface bound water molecules and activated, which provides proton to react with metal surface bound 4-NP to form the final product of 4-AP. Herein, because the $O$ atoms from the nitro group in 4-NP involve the formation of SESs with activated water, nitrogen atom from the nitro group in a favourable position is first attacked by activated proton, thus following the principle of 'first come, first served', the proton from water molecule is a hydrogen source for the final product of 4-AP. Finally, the formed $\mathrm{OH}$ groups are bound to metal surface, which would further react with boron species, leading to the formation of surface bound borate; the surface bound borate would slowly dissolve into solution, and the catalytic active sites are regenerated. This study helps to distinguish various mechanisms proposed in the literature regarding catalytic hydride reduction of $-\mathrm{NO}_{2}$ to $-\mathrm{NH}_{2}$, and the resulting experimental evidence supports the water-channel mediated concerted electron and proton transfer mechanism in the [FeFe]-hydrogenases (Scheme 1c) (39-42). The concept of 'pool or sea of 
elections' formed by SESs may lead to new design principles beyond the conventional metal centered d-band theory of heterogeneous catalysis (49, 62).

Author Contributions: BQS, JFZ, MD and XDH performed the main experiments. KZ conceived and directed the project. $\mathrm{KZ}$ and BQS proposed a new dynamic surface electronic states (SESs) model to understand the nature of catalysis, beyond the metal-centered $\mathrm{d}$ band theory. $\mathrm{KZ}$ and BQS analyzed all the data and co-designed the figures with the help of JFZ. KZ and BOS wrote the manuscript. All authors have read and agreed to the published version of the manuscript.

Acknowledgments: This research was funded by the NSFC (21872053 and 21573074), the Science and Technology Commission of Shanghai Municipality (19520711400), the CAS key laboratory of Low-Coal Conversion Science \& Engineering (KLLCCSE-201702), and the JORISS program, the Postdoctoral Science Foundation of China (2018M640360). K.Z. thanks ENS de Lyon for a temporary position as an invited professor in France. This paper is dedicated to my both tutors of Prof. Ming-Yuan He at ECNU and Prof. Laurent Bonneviot at ENS-Lyon for their long-term cooperations and supports in research and life.

\section{Reference}

1. G. A. Somorjai, A. M. Contreras, M. Montano, R. M. Rioux, Clusters, surfaces, and catalysis. Proc. Natl. Acad. Sci. U.S.A. 103, 10577 (2006).

2. R. Ye, T. J. Hurlburt, K. Sabyrov, S. Alayoglu, G. A. Somorjai, Molecular catalysis science: Perspective on unifying the fields of catalysis. Proc. Natl. Acad. Sci. U.S.A. 113, 5159-5166 (2016).

3. L. Liu, A. Corma, Metal Catalysts for Heterogeneous Catalysis: From Single Atoms to Nanoclusters and Nanoparticles. Chem. Rev. 118, 4981-5079 (2018).

4. C. Gao, F. Lyu, Y. Yin, Encapsulated Metal Nanoparticles for Catalysis. Chem. Rev. 121, 834-881 (2021).

5. P. Liu, R. Qin, G. Fu, N. Zheng, Surface Coordination Chemistry of Metal Nanomaterials. J. Am. Chem. Soc. 139, 2122-2131 (2017).

6. R. Qin, K. Liu, Q. Wu, N. Zheng, Surface Coordination Chemistry of Atomically Dispersed Metal Catalysts. Chem. Rev. 120, 11810-11899 (2020).

7. A. Corma, P. Concepcion, P. Serna, A different reaction pathway for the reduction of aromatic nitro compounds on gold catalysts. Angew. Chem. Int. Ed. 46, 7266-7269 (2007).

8. P. Serna, A. Corma, Transforming Nano Metal Nonselective Particulates into Chemoselective Catalysts for Hydrogenation of Substituted Nitrobenzenes. ACS Catal. 5, 7114-7121 (2015).

9. P. Herves et al., Catalysis by metallic nanoparticles in aqueous solution: model reactions. Chem. Soc. Rev. 41, 5577-5587 (2012).

10. C. Wang, Q. Wang, F. Fu, D. Astruc, Hydrogen Generation upon Nanocatalyzed Hydrolysis of Hydrogen-Rich Boron Derivatives: Recent Developments. Acc. Chem. Res. 53, 2483-2493 (2020).

11. C. Wang, D. Astruc, Recent developments of nanocatalyzed liquid-phase hydrogen generation. Chem. Soc. Rev. 10.1039/d0cs00515k, (2021).

12. W. Xie, R. Grzeschik, S. Schlücker, Metal Nanoparticle-Catalyzed Reduction Using Borohydride in Aqueous Media: A Kinetic Analysis of the Surface Reaction by Microfluidic SERS. Angew. Chem. Int. Ed. 55, 13933-13937 (2016).

13. T. Aditya, A. Pal, T. Pal, Nitroarene reduction: a trusted model reaction to test nanoparticle catalysts. Chem. Commun. 51, 9410-9431 (2015). 
14. E. Menumerov et al., Identifying the True Catalyst in the Reduction of 4-Nitrophenol: A Case Study Showing the Effect of Leaching and Oxidative Etching Using Ag Catalysts. ACS Catal. 8, 8879-8888 (2018).

15. J. Strachan, C. Barnett, A. F. Masters, T. Maschmeyer, 4-Nitrophenol Reduction: Probing the Putative Mechanism of the Model Reaction. ACS Catal. 10, 5516-5521 (2020).

16. Y. Zhao et al., Mechanistic Study of Catalytic Hydride Reduction of $-\mathrm{NO} 2$ to $-\mathrm{NH} 2$ Using Isotopic Solvent and Reducer: The Real Hydrogen Source. J. Phys. Chem. C 123, 15582-15588 (2019).

17. R. Grzeschik et al., On the Overlooked Critical Role of the pH Value on the Kinetics of the 4-Nitrophenol NaBH4-Reduction Catalyzed by Noble-Metal Nanoparticles (Pt, Pd, and $\mathrm{Au}$ ). J. Phys. Chem. C 124, 2939-2944 (2020).

18. S. Shirin, S. Roy, A. Rao, P. P. Pillai, Accelerated Reduction of 4-Nitrophenol: Bridging Interaction Outplays Reducing Power in the Model Nanoparticle-Catalyzed Reaction. J. Phys. Chem. C 124, 19157-19165 (2020).

19. X.-D. Hu, B.-Q. Shan, R. Tao, T.-Q. Yang, K. Zhang, Interfacial Hydroxyl Promotes the Reduction of 4-Nitrophenol by Ag-based Catalysts Confined in Dendritic Mesoporous Silica Nanospheres. J. Phys. Chem. C 125, 2446-2453 (2021).

20. C. Wang et al., Insight into the mechanism of gold-catalyzed reduction of nitroarenes based on the substituent effect and in situ IR. New J. Chem. 41, 3865-3871 (2017).

21. L. Wang et al., Single-site catalyst promoters accelerate metal-catalyzed nitroarene hydrogenation. Nat. Commun. 9, 1362 (2018).

22. Y. Wang et al., Chemoselective Hydrogenation of Nitroaromatics at the Nanoscale Iron(III)-OH-Platinum Interface. Angew. Chem. Int. Ed. 59, 12736-12740 (2020).

23. G. Chen et al., Interfacial electronic effects control the reaction selectivity of platinum catalysts. Nat. Mater. 15, 564-569 (2016).

24. S. Fountoulaki et al., Mechanistic Studies of the Reduction of Nitroarenes by NaBH4 or Hydrosilanes Catalyzed by Supported Gold Nanoparticles. ACS Catal. 4, 3504-3511 (2014).

25. D. Usharani, D. C. Lacy, A. S. Borovik, S. Shaik, Dichotomous Hydrogen Atom Transfer vs Proton-Coupled Electron Transfer During Activation of $\mathrm{X}-\mathrm{H}$ Bonds $(\mathrm{X}=\mathrm{C}, \mathrm{N}, \mathrm{O}$ ) by Nonheme Iron-Oxo Complexes of Variable Basicity. Journal of the American Chemical Society 135, 17090-17104 (2013).

26. Y. Zhang, K. de La Harpe, A. A. Beckstead, R. Improta, B. Kohler, UV-Induced Proton Transfer between DNA Strands. J. Am. Chem. Soc. 137, 7059-7062 (2015).

27. N. Berg, S. Bergwinkl, P. Nuernberger, D. Horinek, R. M. Gschwind, Extended Hydrogen Bond Networks for Effective Proton-Coupled Electron Transfer (PCET) Reactions: The Unexpected Role of Thiophenol and Its Acidic Channel in Photocatalytic Hydroamidations. J. Am. Chem. Soc. 143, 724-735 (2021).

28. L. Zhang, E. Bill, P. M. H. Kroneck, O. Einsle, Histidine-Gated Proton-Coupled Electron Transfer to the CuA Site of Nitrous Oxide Reductase. J. Am. Chem. Soc. 143, 830-838 (2021).

29. R. Tyburski, T. Liu, S. D. Glover, L. Hammarstrom, Proton-Coupled Electron Transfer Guidelines, Fair and Square. J. Am. Chem. Soc. 143, 560-576 (2021).

30. M. T. C. Martins-Costa, J. M. Anglada, J. S. Francisco, M. F. Ruiz-Lopez, The Aqueous Surface as an Efficient Transient Stop for the Reactivity of Gaseous NO2 in Liquid Water. J. Am. Chem. Soc. 142, 20937-20941 (2020). 
31. S. Hammes-Schiffer, A. A. Stuchebrukhov, Theory of Coupled Electron and Proton Transfer Reactions. Chem. Rev. 110, 6939-6960 (2010).

32. D. R. Weinberg et al., Proton-Coupled Electron Transfer. Chem. Rev. 112, 4016-4093 (2012).

33. O. Lampret et al., The roles of long-range proton-coupled electron transfer in the directionality and efficiency of [FeFe]-hydrogenases. Proc. Natl. Acad. Sci. U.S.A. 117, 20520-20529 (2020).

34. B. J. Murphy et al., Discovery of Dark pH-Dependent $\mathrm{H}(+)$ Migration in a [NiFe]-Hydrogenase and Its Mechanistic Relevance: Mobilizing the Hydrido Ligand of the Ni-C Intermediate. J. Am. Chem. Soc. 137, 8484-8489 (2015).

35. C. Lorent et al., Shedding Light on Proton and Electron Dynamics in [FeFe] Hydrogenases. J. Am. Chem. Soc. 142, 5493-5497 (2020).

36. G. Berggren et al., Biomimetic assembly and activation of [FeFe]-hydrogenases. Nature 499, 66-69 (2013)

37. A. C. Ghosh, C. Duboc, M. Gennari, Synergy between metals for small molecule activation: Enzymes and bio-inspired complexes. Coordin. Chem. Rev. 428, 213606 (2021).

38. W. Lubitz, H. Ogata, O. Rudiger, E. Reijerse, Hydrogenases. Chem. Rev. 114, 4081-4148 (2014).

39. J. C. Fontecilla-Camps, A. Volbeda, C. Cavazza, Y. Nicolet, Structure/Function Relationships of [NiFe]- and [FeFe]-Hydrogenases. Chem. Rev. 107, 4273-4303 (2007).

40. S. Dementin et al., A glutamate is the essential proton transfer gate during the catalytic cycle of the [NiFe] hydrogenase. J. Biol. Chem. 279, 10508-10513 (2004).

41. M. McCullagh, G. A. Voth, Unraveling the role of the protein environment for [FeFe]-hydrogenase: a new application of coarse-graining. J. Phys. Chem. B 117, 4062-4071 (2013).

42. O. Sode, G. A. Voth, Electron transfer activation of a second water channel for proton transport in [FeFe]-hydrogenase. J. Chem. Phys. 141, 22D527 (2014).

43. Y. J. Yu et al., Facile synthesis of size controllable dendritic mesoporous silica nanoparticles. ACS Appl. Mater. Interfaces 6, 22655-22665 (2014).

44. K. Zhang et al., Facile large-scale synthesis of monodisperse mesoporous silica nanospheres with tunable pore structure. J. Am. Chem. Soc. 135, 2427-2430 (2013).

45. T.-Q. Yang et al., Interfacial electron transfer promotes photo-catalytic reduction of 4-nitrophenol by Au/Ag2O nanoparticles confined in dendritic mesoporous silica nanospheres. Catal. Sci. Technol. 9, 5786-5792 (2019).

46. L. Sun et al., Multifaceted Gold-Palladium Bimetallic Nanorods and Their Geometric, Compositional, and Catalytic Tunabilities. ACS Nano. 11, 3213-3228 (2017).

47. R. E. Davis, E. Bromels, C. L. Kibby, Boron Hydrides. III. Hydrolysis of Sodium Borohydride in Aqueous Solution. J. Am. Chem. Soc. 84, 885-892 (1962).

48. R. E. Dessy, E. Grannen, The Kinetics and Mechanism of the Reaction of Borohydrides with Weak Acids1. J. Am. Chem. Soc. 83, 3953-3958 (1961).

49. T. Q. Yang et al., $\mathrm{P}$ band intermediate state (PBIS) tailors photoluminescence emission at confined nanoscale interface. Commun Chem 2, 132 (2019).

50. Y. Taiqun, P. Bo, Z. Jiafeng, S. Bingqian, Z. Kun, Hydrogen-Bonded Water Clusters Confined in Nanocavity as Bright Color Emitters. ChemRxiv (2020).

51. H. Xiao-Dan, Y. Taiqun, S. Bingqian, P. Bo, Z. Kun, Topological Excitation of Singly Hydrated Hydroxide Complex in Confined Sub-Nanospace for Bright Color Emission and Heterogeneous 
Catalysis. ChemRxiv (2020).

52. R. Hoffmann, Interaction of orbitals through space and through bonds. Acc. Chem. Res. 4, 1-9 (1971).

53. G. Guella, C. Zanchetta, B. Patton, A. Miotello, New Insights on the Mechanism of Palladium-Catalyzed Hydrolysis of Sodium Borohydride from 11B NMR Measurements. J. Phys. Chem. B 110, 17024-17033 (2006).

54. G. Guella, B. Patton, A. Miotello, Kinetic Features of the Platinum Catalyzed Hydrolysis of Sodium Borohydride from 11B NMR Measurements. J. Phys. Chem. C 111, 18744-18750 (2007).

55. G. Guella, C. Zanchetta, B. Patton, A. Miotello, New Insights on the Mechanism of Palladium-Catalyzed Hydrolysis of Sodium Borohydride from 11B NMR Measurements. The Journal of Physical Chemistry B 110, 17024-17033 (2006).

56. B. Hammer, J. K. Norskov, Why gold is the noblest of all the metals. Nature 376, 238-240 (1995).

57. B. Liu, A. Rose, N. Zhang, Y.-Y. Hu, M. Ma, Efficient Co-Nanocrystal-Based Catalyst for Hydrogen Generation from Borohydride. J. Phys. Chem. C 121, 12610-12616 (2017).

58. L. M. Epstein, E. S. Shubina, New types of hydrogen bonding in organometallic chemistry. Coordin. Chem. Rev. 231, 165-181 (2002).

59. N. V. Belkova, L. M. Epstein, O. A. Filippov, E. S. Shubina, Hydrogen and Dihydrogen Bonds in the Reactions of Metal Hydrides. Chem. Rev. 116, 8545-8587 (2016).

60. S. Winstein, D. S. Trifan, THE STRUCTURE OF THE BICYCLO[2,2,1]2-HEPTYL (NORBORNYL) CARBONIUM ION. J. Am. Chem. Soc. 71, 2953-2953 (1949).

61. F. Scholz et al., Crystal Structure Determination of the Nonclassical 2-Norbornyl Cation. Science 341, 62 (2013).

62. A. J. Medford et al., From the Sabatier principle to a predictive theory of transition-metal heterogeneous catalysis. J. Catal. 328, 36-42 (2015).

\section{Graphic abstract}


近水拱合牲得月 


\section{Supporting Information}

\section{Surface Electronic State Mediates Proton Transfer at Metal Nanoscale Interface for Catalytic Hydride Reduction of $-\mathrm{NO}_{2}$ to $-\mathrm{NH}_{2}$}

Bing-Qian Shan, ${ }^{1}$ Jia-Feng Zhou, ${ }^{1}$ Meng Ding, ${ }^{1}$ Xiao-Dan Hu, ${ }^{1}$ Kun Zhang ${ }^{1,2,3 *}$

${ }^{1}$ Shanghai Key Laboratory of Green Chemistry and Chemical Processes, Laboratory of Interface and Water Science, College of Chemistry and Molecular Engineering, East China Normal University, Shanghai 200062, China;

${ }^{2}$ Laboratoire de chimie, Ecole Normale Supérieure de Lyon, Institut de Chimie de Lyon, Université de Lyon, 46 Allée d'italie, 69364 Lyon cedex 07, France;

${ }^{3}$ Shandong Provincial Key Laboratory of Chemical Energy Storage and Novel Cell Technology, School of Chemistry and Chemical Engineering, Liaocheng University, Liaocheng, 252059, Shandong, P. R. China.

* Correspondence: kzhang@chem.ecnu.edu.cn (K.Z.) 


\section{Table of Contents}

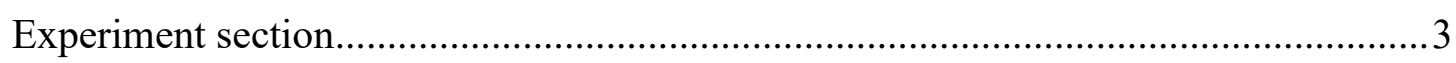

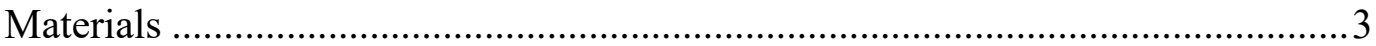

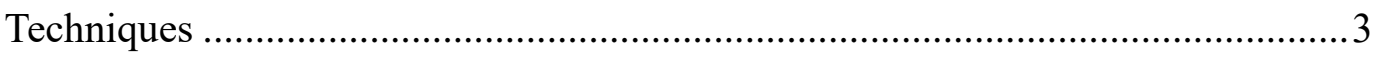

Synthesis of dendritic mesoporous silica nanospheres (DMSNs) supports ............. 3

Synthesis of mesoporous silica nanopaticles loaded with different metal NPs ......3

Synthesis of Ag loaded zeolite (Ag@LTA)......................................................... 4

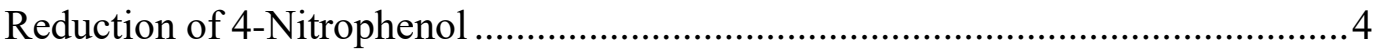

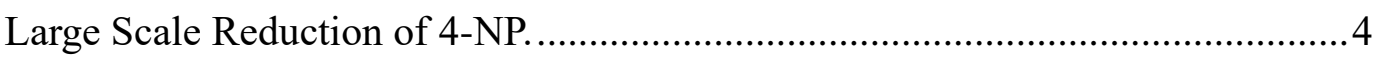

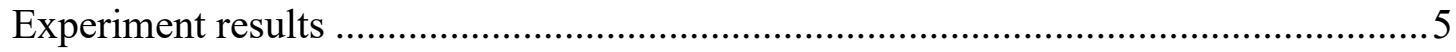

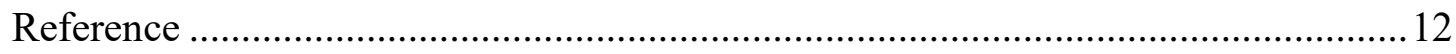




\section{Experiment section}

\section{Materials}

(3-aminopropyl) trimethoxysilane (APTMS, 97\%) were purchased from Aladdin. Cetyltrimethylammonium tosylate (CTATos) was purchased from MERK. Triethanolamine $\left(\mathrm{TEAH}_{3}\right)$, tetraethylorthosilicate (TEOS), sodium hydroxide $(\mathrm{NaOH}, \mathrm{AR})$, sodium borohydride $\left(\mathrm{NaBH}_{4}, \mathrm{AR}\right)$, hydrochloric acid (HCI, 36\% 38\%), ethanol (EtOH, $\left.\mathrm{AR}\right)$ and silver nitrate $\left(\mathrm{AgNO}_{3}\right.$, AR), Chloroplatinic acid $\left(\mathrm{H}_{2} \mathrm{PtCl}_{6}, 37 \mathrm{wt} \% \mathrm{Pt}\right)$ were purchased from Sinopharm Chemical Reagent Co., Ltd. Potassium tetrachloroplatinate $\left(\mathrm{K}_{2} \mathrm{PdCl}_{6}, 32.6 \mathrm{wt} \% \mathrm{Pd}\right)$, Sodium borodeuteride $\left(\mathrm{NaBD}_{4}\right)$, Deuterium oxide $\left(\mathrm{D}_{2} \mathrm{O}, 99 \% \mathrm{D}\right)$ and Deuterium sodium hydroxide $(\mathrm{NaOD})$. were achieved from Shanghai Macklin Biochemical.

\section{Techniques}

The X-ray diffraction (XRD) patterns were required using a Rigaku Ultima Discover X-Ray Diffractometer at a wavelength of $\mathrm{Cu} \mathrm{K} \alpha(1.5405 \AA)$. TEM analyses were performed by using a JEOL 2010F microscope equipped with a field-emission gun and operating at $200 \mathrm{kV}$. FTIR spectra were recorded on a Nicolet FTIR spectrometer (NEXUS 670) by diluting the sample with fine $\mathrm{KBr}$ powder and pressing into a pellet. Fluorescence was measured by using a FluorMax-4 fluorimeter (Horiba, Japan). Ultraviolet visible (UV-vis) spectroscopy was conducted with a Shimadzu UV-2700 UV-vis spectrophotometer and the $\mathrm{BaSO}_{4}$ was used as reference. Fluorescence was measured by using a RF-6000 fluorimeter. ${ }^{1} \mathrm{H}$ NMR spectra were recorded on Bruker $400 \mathrm{MHz}$ Spectrometer and Bruker $300 \mathrm{MHz}$ Spectrometer at $298 \mathrm{~K}$.

\section{Synthesis of dendritic mesoporous silica nanospheres (DMSNs) supports}

DMSNs were synthesized according to the literature report(1). The DMSNs were treated by $\mathrm{HCl}$ and then functionalized by aminopropyl before grafting metal nanoparticles. In a typical process, $2 \mathrm{~g}$ of DMSNs, $3.36 \mathrm{~mL}$ of $1 \mathrm{M} \mathrm{HCl}$ and $80 \mathrm{~mL}$ of EtOH were added into a round-bottom flask, the mixture was refluxed with stirring at $60^{\circ} \mathrm{C}$ for $1 \mathrm{~h}$. The solid was dried at $80^{\circ} \mathrm{C}$ after filtered. Then, $1.5 \mathrm{~g}$ of $\mathrm{HCl}$ washed DMSNs, $2.61 \mathrm{~g}$ of APTMS and $60 \mathrm{~mL}$ EtOH were introduced into a round-bottom flask and maintained at $80^{\circ} \mathrm{C}$ for $12 \mathrm{~h}$ in an oil bath with stirring under reflux condition. The solution was filtered and the solid was dried at $80^{\circ} \mathrm{C}$.

\section{Synthesis of mesoporous silica nanopaticles loaded with different metal NPs}

In a $200 \mathrm{~mL}$ beaker, $1 \mathrm{~g}$ of amino-functionalized DMSNs was suspended in $80 \mathrm{~mL}$ alcohol, subsequently add $13.27 \mathrm{~mL}$ of $7.72 \mathrm{mM} \mathrm{H}_{2} \mathrm{PtCl}_{6} \cdot 6 \mathrm{H}_{2} \mathrm{O}$ aqueous or $10 \mathrm{~mL}$ of $18.8 \mathrm{mM} \mathrm{K}_{2} \mathrm{PdCl}_{6}$ solution. After being stirred at room temperature for $12 \mathrm{~h}$ in dark, excess of $\mathrm{NaBH}_{4}$ was added at once. The obtained product was filtered and washed repeatedly with deionized $\mathrm{H}_{2} \mathrm{O}$ and dried overnight at $80^{\circ} \mathrm{C}$. The products were denoted as Pt@DMSNs, Pd@DMSNs respectively. In a 200 $\mathrm{mL}$ beaker, $1 \mathrm{~g}$ of amino-functionalized DMSNs was suspended in $100 \mathrm{~mL} \mathrm{H}_{2} \mathrm{O}$ and treated by ultrasound for 30 minutes, and subsequently $3.7 \mathrm{~mL}$ of $50 \mathrm{mM} \mathrm{AgNO}_{3}$ solution was added. After being stirred at room temperature for $3 \mathrm{~h}$ in dark, excess of $\mathrm{NaBH}_{4}$ was added at once. Then the mixture was stirred unceasingly for $30 \mathrm{~min}$. The obtained product was filtered and washed repeatedly with deionized $\mathrm{H}_{2} \mathrm{O}$ and dried overnight at $80^{\circ} \mathrm{C}$. The products were denoted as Ag@DMSNs. Ag $@$ DMSNs was obtained without $\mathrm{NaBH}_{4}$ reduction. Ag-OH@DMSNs were prepared as according to the above method, except that after adding excess $\mathrm{NaBH}_{4}$ and stirring 30 
min, $10 \mathrm{~mL}$ of $1 \mathrm{M} \mathrm{NaOH}$ was added and stirred for $30 \mathrm{~min}$. The other products which contain different concentrations of $\mathrm{NaOH}(0.01 \mathrm{M}, 0.1 \mathrm{M}, 2 \mathrm{M})$ were synthesized (2).

\section{Synthesis of Ag loaded zeolite (Ag@LTA)}

The silver loaded zeolite Ag-LTA(Na) was prepared by suspending $1 \mathrm{~g}$ zeolite materia ( Na-LTA, $\mathrm{Si} / \mathrm{Al}=1 \sim 2)$ in $500 \mathrm{~mL}$ of a silver nitrate aqueous solution, the suspension was then agitated for 2 hours in the dark. The powder was recovered by filtration using a Büchner filter and washed several times with milliQ water. Then the sample was calcined at $80^{\circ} \mathrm{C}\left(5^{\circ} \mathrm{C} \mathrm{min}^{-1}\right)(3)$. After heat treatment the sample was cooled under ambient conditions, allowing the sample to reach a fully hydrated state, and stored in the dark for further analysis.

\section{Reduction of 4-Nitrophenol}

Aqueous solutions of $\mathrm{H}_{2} \mathrm{O}(2.5 \mathrm{~mL})$, 4-NP $(0.2 \mathrm{~mL}, 2.5 \mathrm{mM})$ and $\mathrm{NaBH}_{4}(0.4 \mathrm{~mL}, 250 \mathrm{mM})$ were added into a quartz cuvette under stirring. Subsequently, a certain amount $(30 \mu \mathrm{L})$ of aqueous solution of catalyst $(5 \mathrm{mg} / \mathrm{mL})$ was added. As the reaction progressed, the bright yellow solution gradually faded. The reaction was scanned by UV-vis spectrum repeatedly from $500 \mathrm{~nm}$ to 250 $\mathrm{nm}$ over the whole course to record the changes. To test the effect of hydroxide content on the reaction activity, $2.5 \mathrm{~mL}$ of $\mathrm{NaOH}(0.01 \mathrm{M}, 0.1 \mathrm{M}, 1 \mathrm{M}, 2 \mathrm{M})$ was added instead of $2.5 \mathrm{~mL} \mathrm{H}_{2} \mathrm{O}$. In the deuterium isotopic experiments, the reduction was conducted under the same conditions except for the use of $\mathrm{NaBD}_{4}$ and/or $\mathrm{D}_{2} \mathrm{O}$. To test the reaction kinetics in different kinds of solvents, the reduction was also conducted in ethanol, and acetonitrile, respectively.

\section{Large Scale Reduction of 4-NP.}

To obtain more reduction products of 4-AP for spectroscopic measurements, large scale synthesis was carried out according to the literature(4). First, $12 \mathrm{mg}$ of 4-NP was dissolved in 4 $\mathrm{mL}$ of $\mathrm{H}_{2} \mathrm{O}$ under magnetic stirring in the tube, followed by addition of a $1 \mathrm{~mL} 5 \mathrm{mg} / \mathrm{mL}$ catalysts. Then, $24.0 \mathrm{mg}$ of $\mathrm{NaBH}_{4}$ was dissolved in $1 \mathrm{~mL}$ of $\mathrm{H}_{2} \mathrm{O}$ and the solution was immediately added into the tube. After stirring for about $10 \mathrm{~min}$, the color of the mixture became colorless. The complete reduction was confirmed by UV-vis absorption spectroscopic measurement, in which the peak of 4-NP at about $400 \mathrm{~nm}$ disappeared. Afterward, the mixture was extracted with ethyl acetate three times and the products in the organic phase were collected and dried over anhydrous sodium sulfate $\left(\mathrm{NaSO}_{4}\right)$. Finally, the reduction products were obtained after evaporating the solvent under reduced pressure. 


\section{Experiment results}

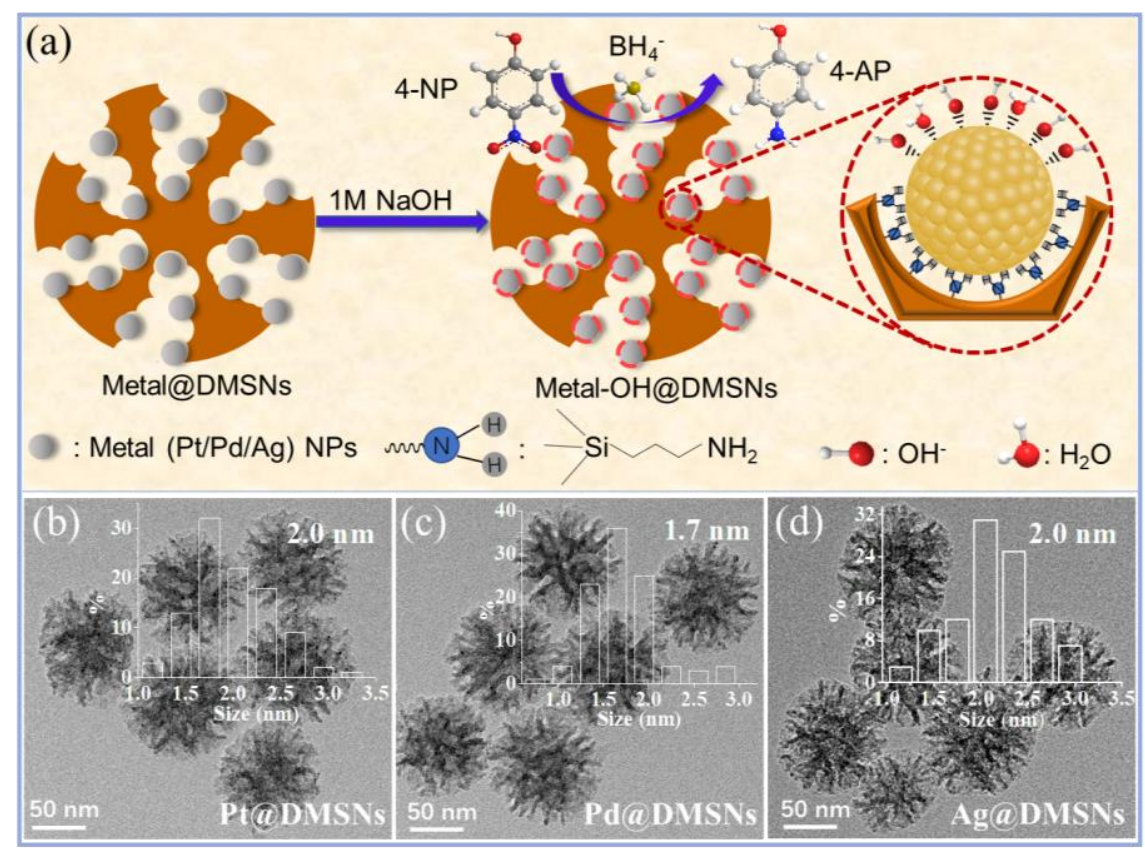

Figure S1. (a) Schematic illustration of the synthesis procedure of Pt, Pd and Ag NPs supported DMSNs catalysts. TEM image of Pt@DMSNs (b), Pd@DMSNs (c) and Ag@DMSNs (d). The inset is the particle size distribution. The average diameter for Pt, Pd and Ag NPs is about 2.0, 1.7 and $4.1 \mathrm{~nm}$, respectively.
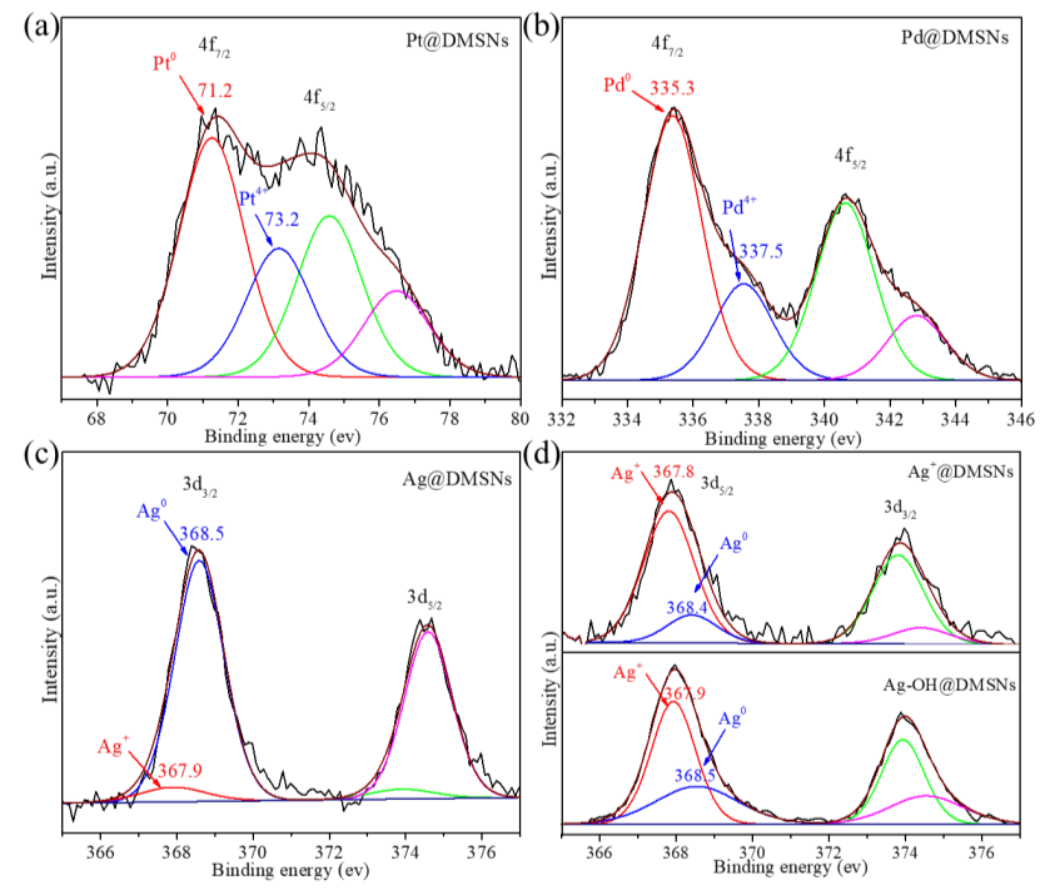

Figure S2. XPS spectra of Pt (a), Pd (b) and Ag (c) NPs supported DMSNs catalysts. XPS spectra of $\mathrm{Ag}^{+} @$ DMSNs catalyst without the last step of metal reduction and Ag-OH@DMSNs with $\mathrm{OH}^{-}$ pre-adsorbed (d).

Table S1. Surface compositions of catalysts determined by XPS. 


\begin{tabular}{|c|c|c|c|c|}
\hline \multirow{2}{*}{ Sample } & \multicolumn{2}{|c|}{ Pt component $(\%)$} & \multicolumn{2}{|c|}{ Pt position (eV) } \\
\hline & $\mathrm{Pt}^{0}$ & $\mathrm{Pt}^{4+}$ & $\mathrm{Pt}^{0}$ & $\mathrm{Pt}^{4+}$ \\
\hline \multirow[t]{3}{*}{ Pt@DMSNs } & 65.2 & 34.8 & 71.2 & 73.2 \\
\hline & \multicolumn{2}{|c|}{ Pd component (\%) } & \multicolumn{2}{|c|}{ Pd position (eV) } \\
\hline & $\mathrm{Pd}^{0}$ & $\mathrm{Pd}^{4+}$ & $\mathrm{Pd}^{0}$ & $\mathrm{Pd}^{4+}$ \\
\hline \multirow[t]{3}{*}{ Pd@DMSNs } & 73.3 & 26.7 & 335.4 & 337.5 \\
\hline & \multicolumn{2}{|c|}{ Ag component $(\%)$} & \multicolumn{2}{|c|}{ Ag position $(\mathrm{eV})$} \\
\hline & $\mathrm{Ag}^{0}$ & $\mathrm{Ag}^{+}$ & $\mathrm{Ag}^{0}$ & $\mathrm{Ag}^{+}$ \\
\hline Ag@DMSNs & 92.6 & 7.4 & 368.5 & 367.9 \\
\hline $\mathrm{Ag}^{+} @ \mathrm{DMSNs}$ & 17.2 & 82.8 & 368.4 & 367.8 \\
\hline Ag-OH@DMSNs & 36.3 & 63.7 & 368.5 & 367.9 \\
\hline
\end{tabular}

Table S2 Comparison of recent reports on Ag-based catalysts catalyzed reduction of 4-NP by $\mathrm{NaBH}_{4}$.

\begin{tabular}{ccccc}
\hline Catalyst & Catalyst used $(\mathrm{mg})$ & $K^{a}\left(10^{-3} \mathrm{~s}^{-1}\right)$ & $K / M^{b}\left(\mathrm{~s}^{-1} \mathrm{~g}^{-1}\right)$ & Ref. \\
\hline $\mathrm{Ag}-\mathrm{Fe}_{2} \mathrm{O}_{3}$ & 2.00 & 4.90 & 2.45 & $(5)$ \\
$\mathrm{Fe}_{3} \mathrm{O}_{4} @ \mathrm{SiO}_{2}-\mathrm{Ag}$ & 1.00 & 7.67 & 7.67 & $(6)$ \\
$\mathrm{Ag} @ \mathrm{hm}-\mathrm{SiO}_{2}$ & 2.00 & 18.00 & 9.00 & $(7)$ \\
$\mathrm{AgNPs} / \mathrm{PD} / \mathrm{PANFP}$ & 0.14 & 2.28 & 16.31 & $(8)$ \\
$\mathrm{SiO}$ @ Ag-2 & 0.50 & 9.32 & 18.64 & $(9)$ \\
$\mathrm{Ag} 2.4 \% \mathrm{Ni} @ \mathrm{SBA}-16 \mathrm{C}$ & 0.40 & 37.90 & 94.80 & $(10)$ \\
$\mathrm{Pt} @ \mathrm{Ag} \mathrm{NPs}$ & 0.05 & 5.92 & 118.40 & $(11)$ \\
$2.0 \% \mathrm{Ag}-\mathrm{OH}-\mathrm{DMMNs}$ & 0.15 & 21.17 & 141.13 & $(2)$ \\
$\mathrm{Ag}-\mathrm{OMS}-\mathrm{C}$ & 0.20 & 30.00 & 150.00 & $(12)$ \\
Ag@LTA & 0.15 & 22.67 & 151.13 & this work \\
\hline
\end{tabular}

${ }^{a}$ The reaction rate constant.

${ }^{b}$ The reaction rate constant per total weight of used catalyst.

(a)

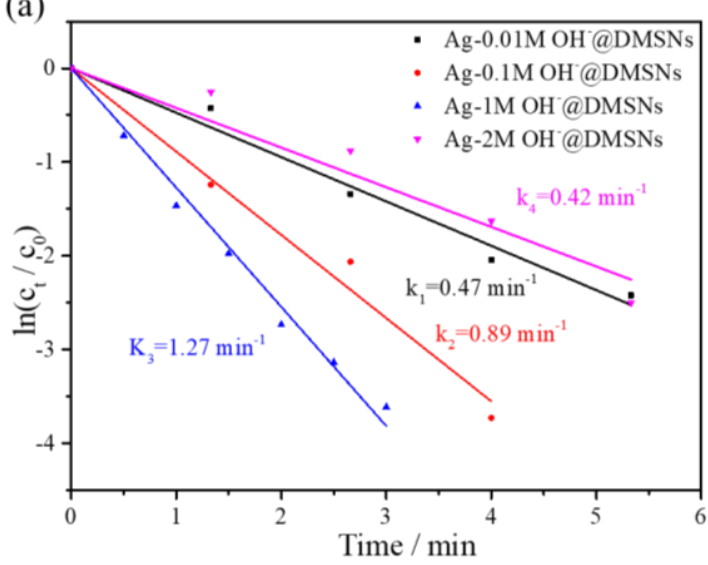

(b)

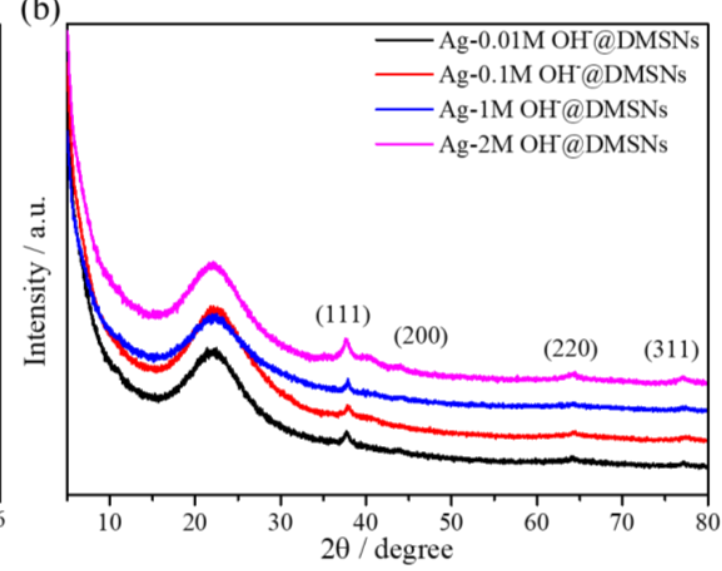

Figure S3. Plot of $\ln \left(\mathrm{C}_{t} / \mathrm{C}_{0}\right)$ against the reaction time of the reduction of 4-NP (a) and XRD patterns (b) of different content of $\mathrm{OH}^{-}$was introduced into $\mathrm{Ag} @$ DMSNs. 


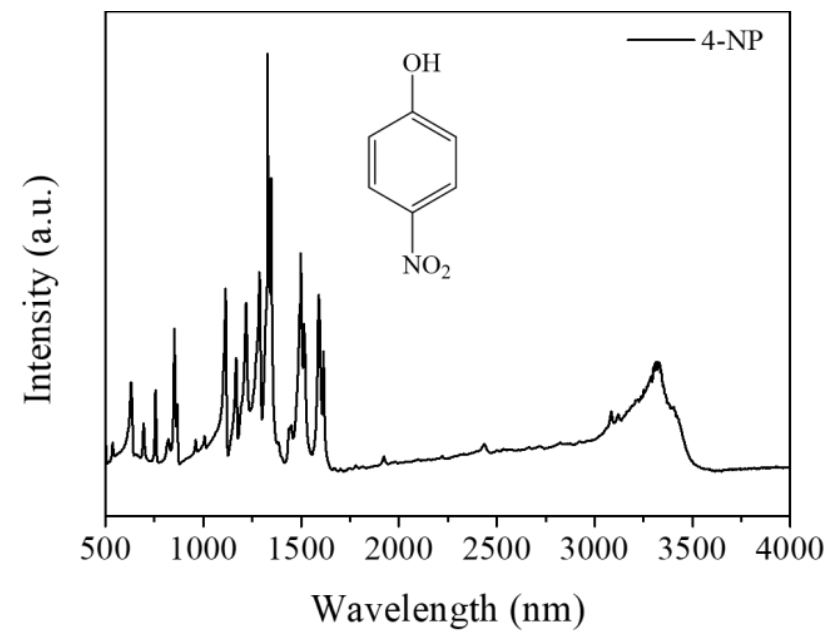

Figure S4. FTIR spectrum of commercial 4-NP.

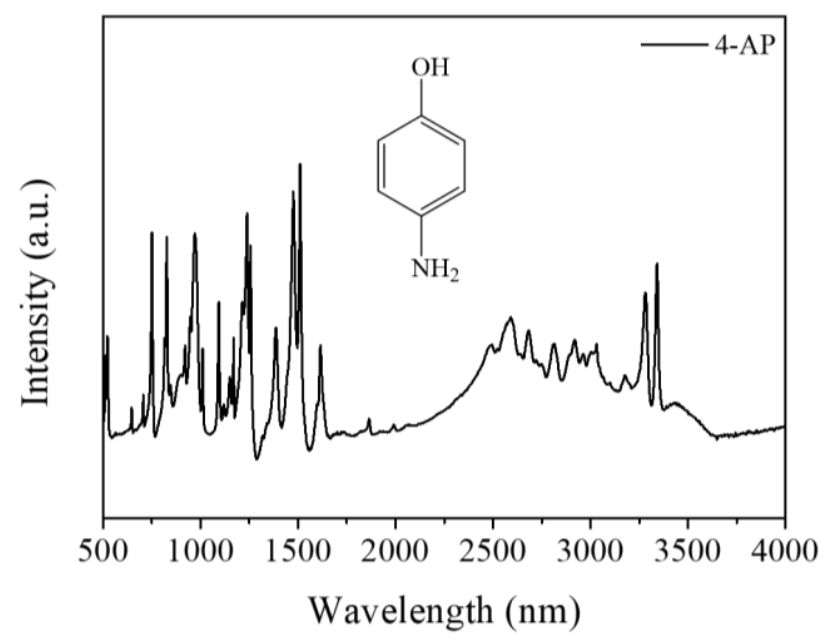

Figure S5. FTIR spectrum of commercial 4-AP.
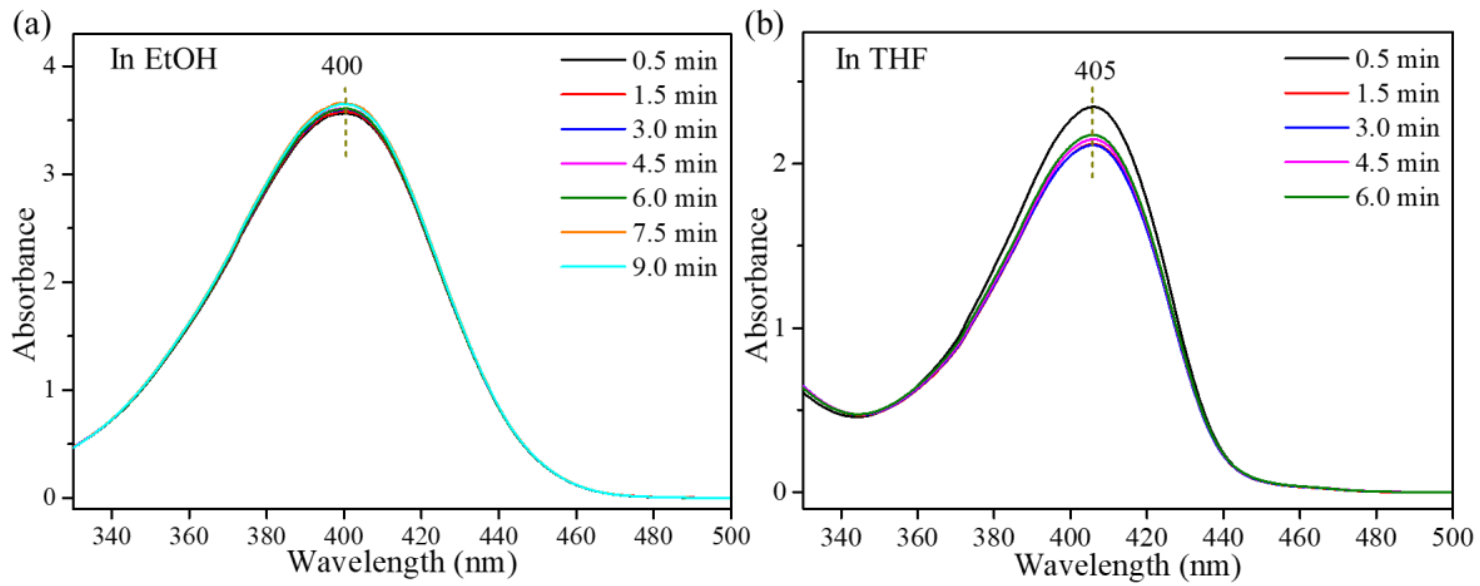

Figure S6. UV-vis absorption spectra of Ag@DMSNs reduction of 4-NP using $\mathrm{NaBH}_{4}$ in ethanol. 


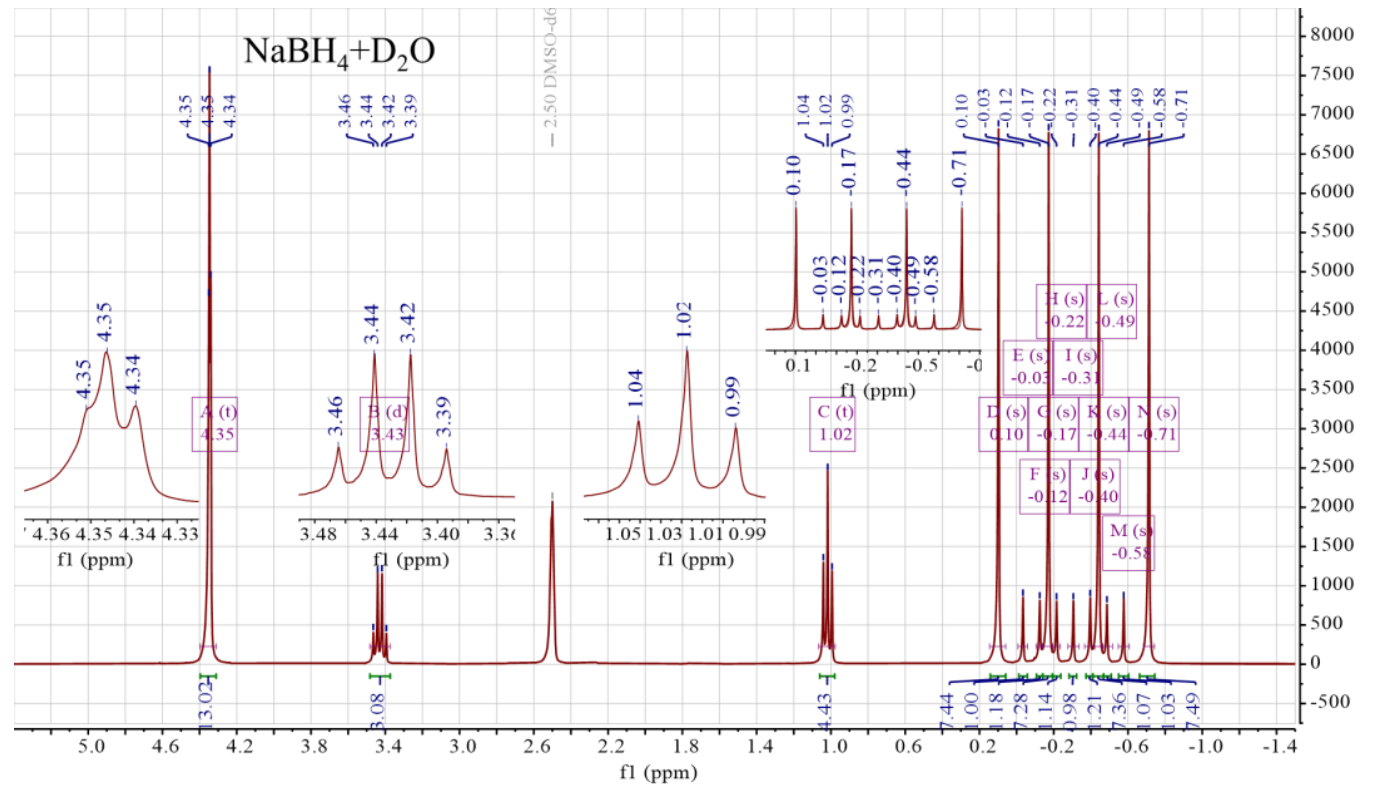

Figure S7. ${ }^{1} \mathrm{H}$ NMR spectrum of $\mathrm{NaBH}_{4}$ and $\mathrm{D}_{2} \mathrm{O}$.

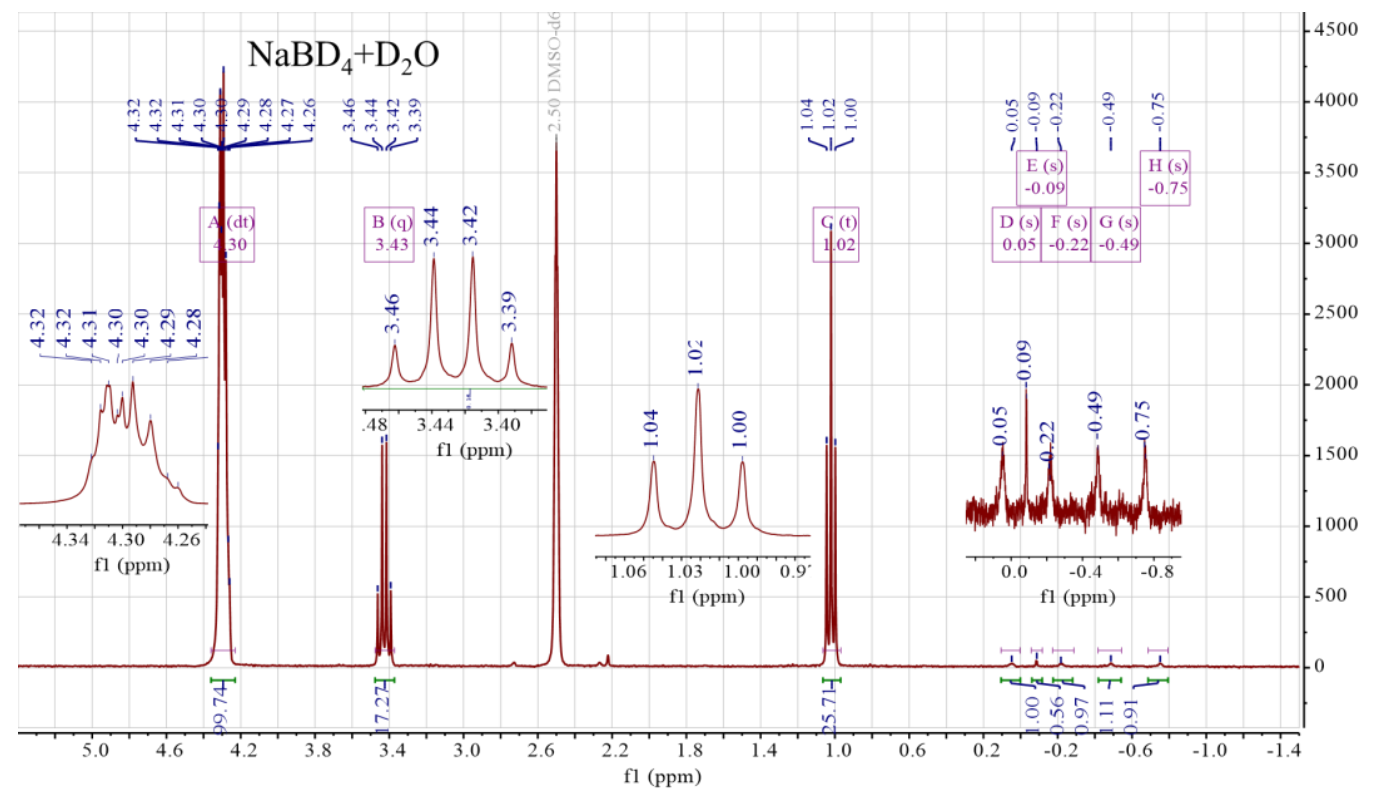

Figure S8. ${ }^{1} \mathrm{H}$ NMR spectrum of $\mathrm{NaBD}_{4}$ and $\mathrm{D}_{2} \mathrm{O}$. 


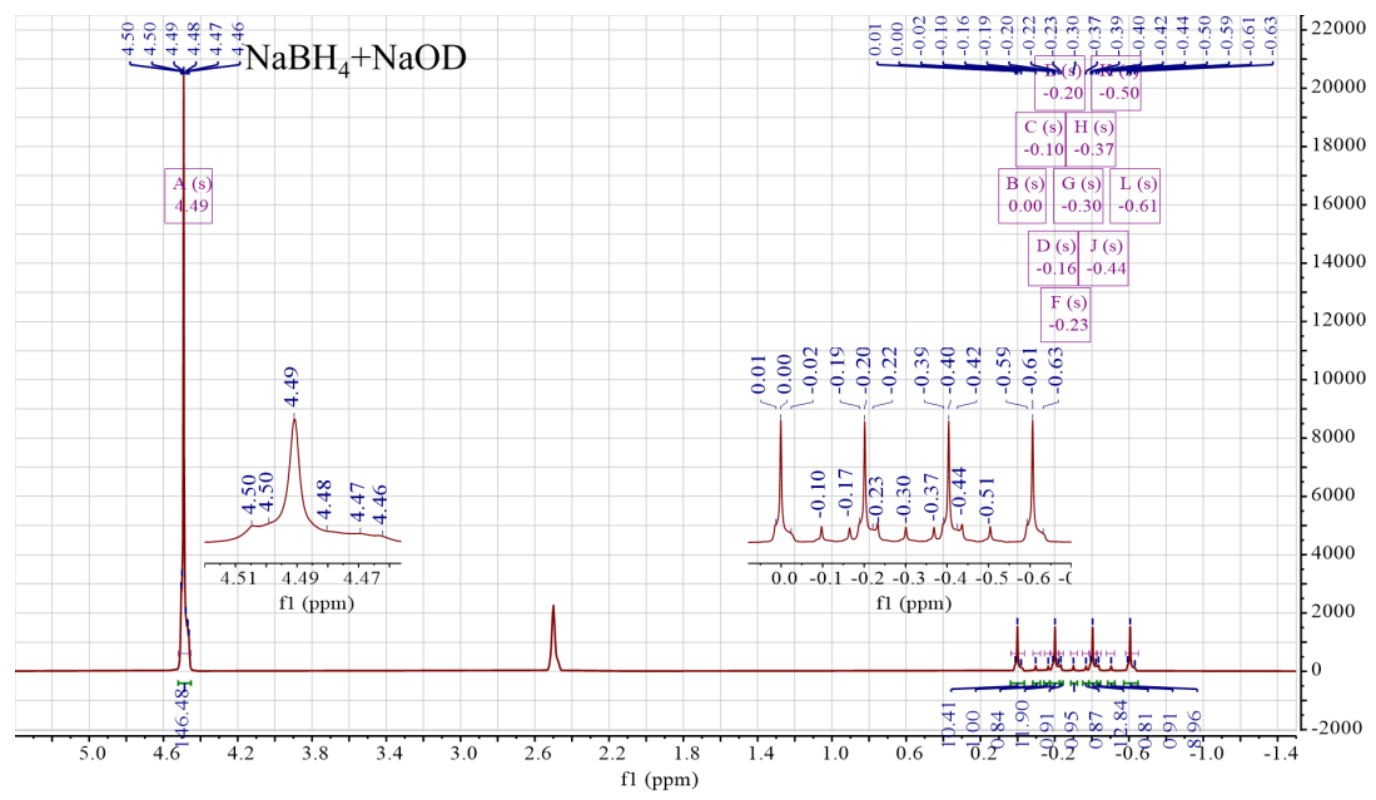

Figure S9. ${ }^{1} \mathrm{H}$ NMR spectrum of $\mathrm{NaBH}_{4}$ and $\mathrm{NaOD}$.

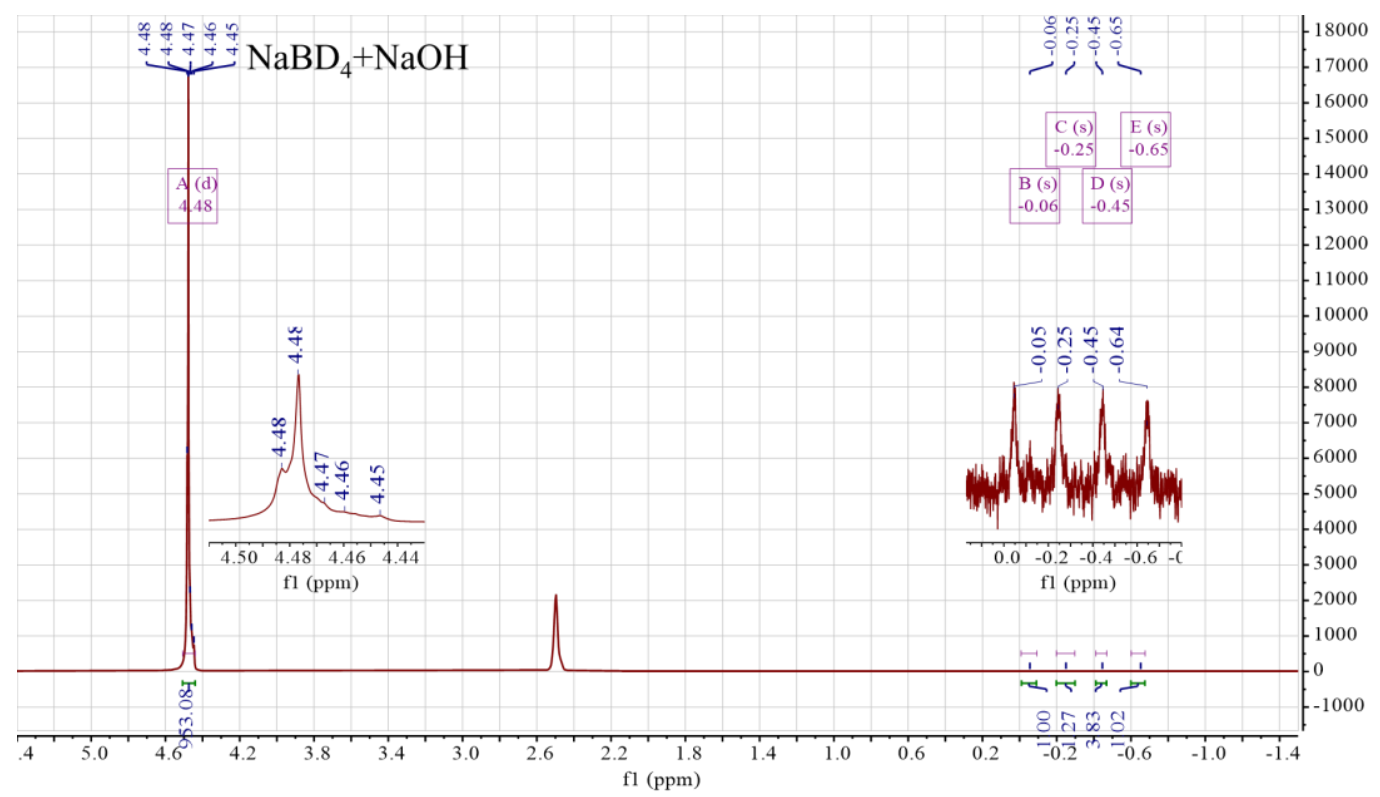

Figure S10. ${ }^{1} \mathrm{H}$ NMR spectrum of $\mathrm{NaBD}_{4}$ and $\mathrm{NaOH}$. 


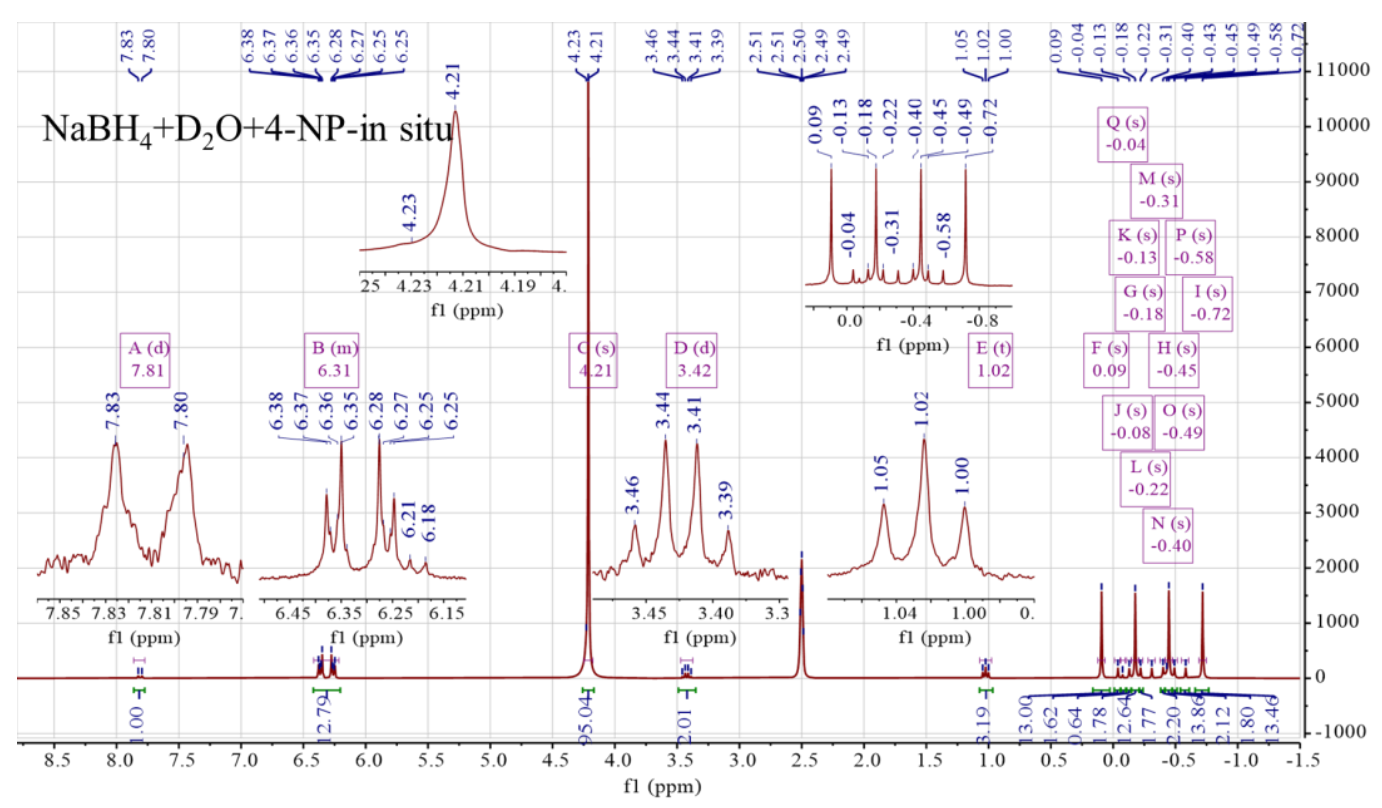

Figure S11. ${ }^{1} \mathrm{H}$ NMR spectrum of the reduction product using $\mathrm{NaBH}_{4}$ and $\mathrm{D}_{2} \mathrm{O}$ in the middle of the reaction.

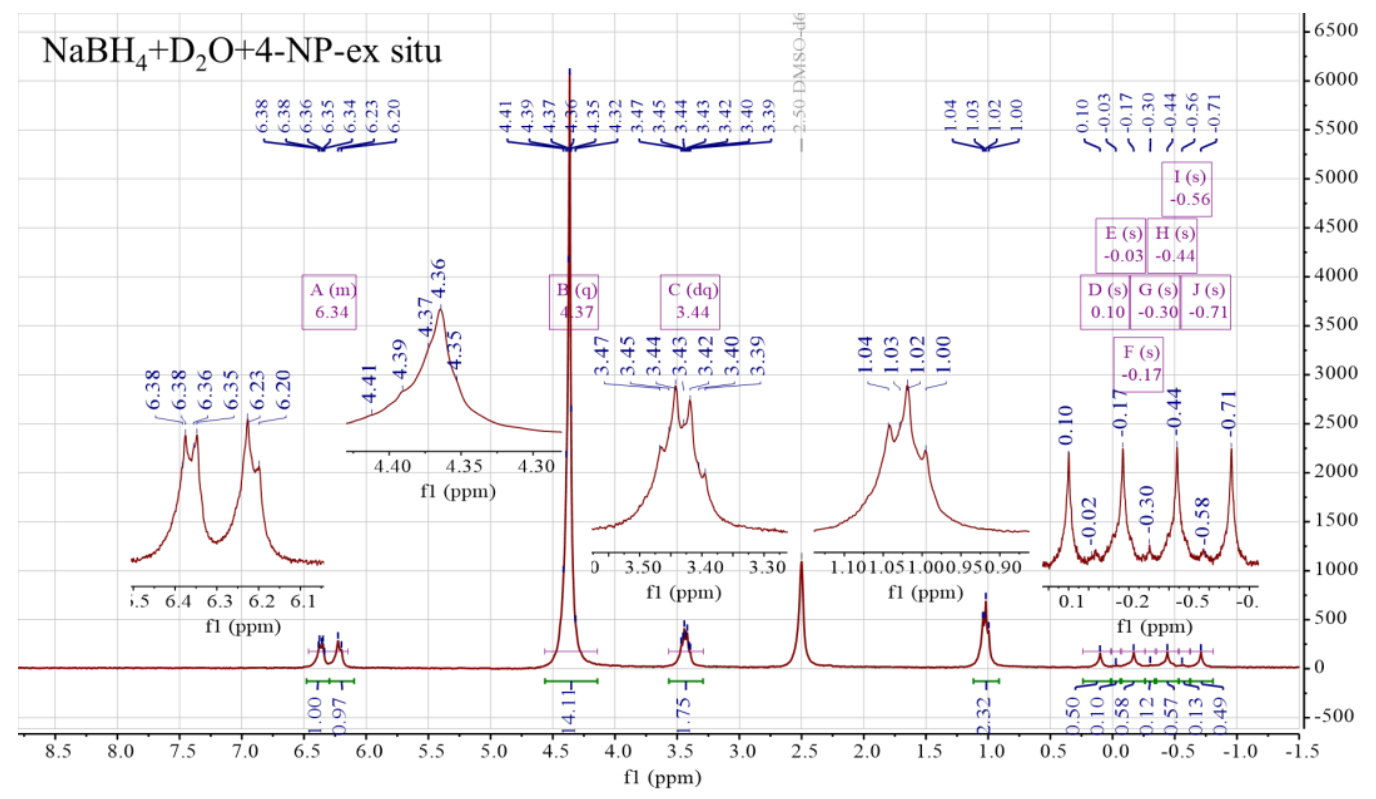

Figure S12. ${ }^{1} \mathrm{H}$ NMR spectrum of the reduction product using $\mathrm{NaBH}_{4}$ and $\mathrm{D}_{2} \mathrm{O}$ after the reaction. 


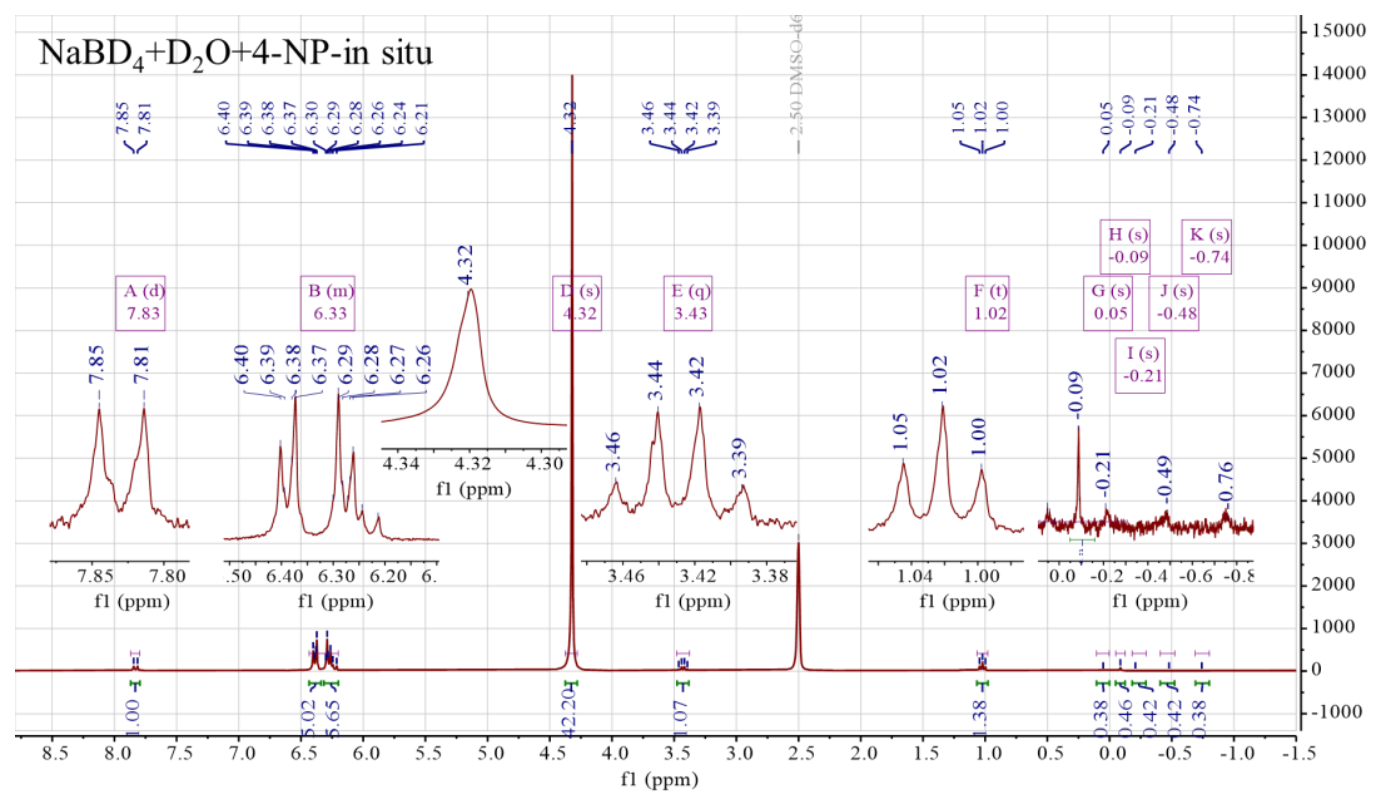

Figure S13. ${ }^{1} \mathrm{H}$ NMR spectrum of the reduction product using $\mathrm{NaBD}_{4}$ and $\mathrm{D}_{2} \mathrm{O}$ in the middle of the reaction.

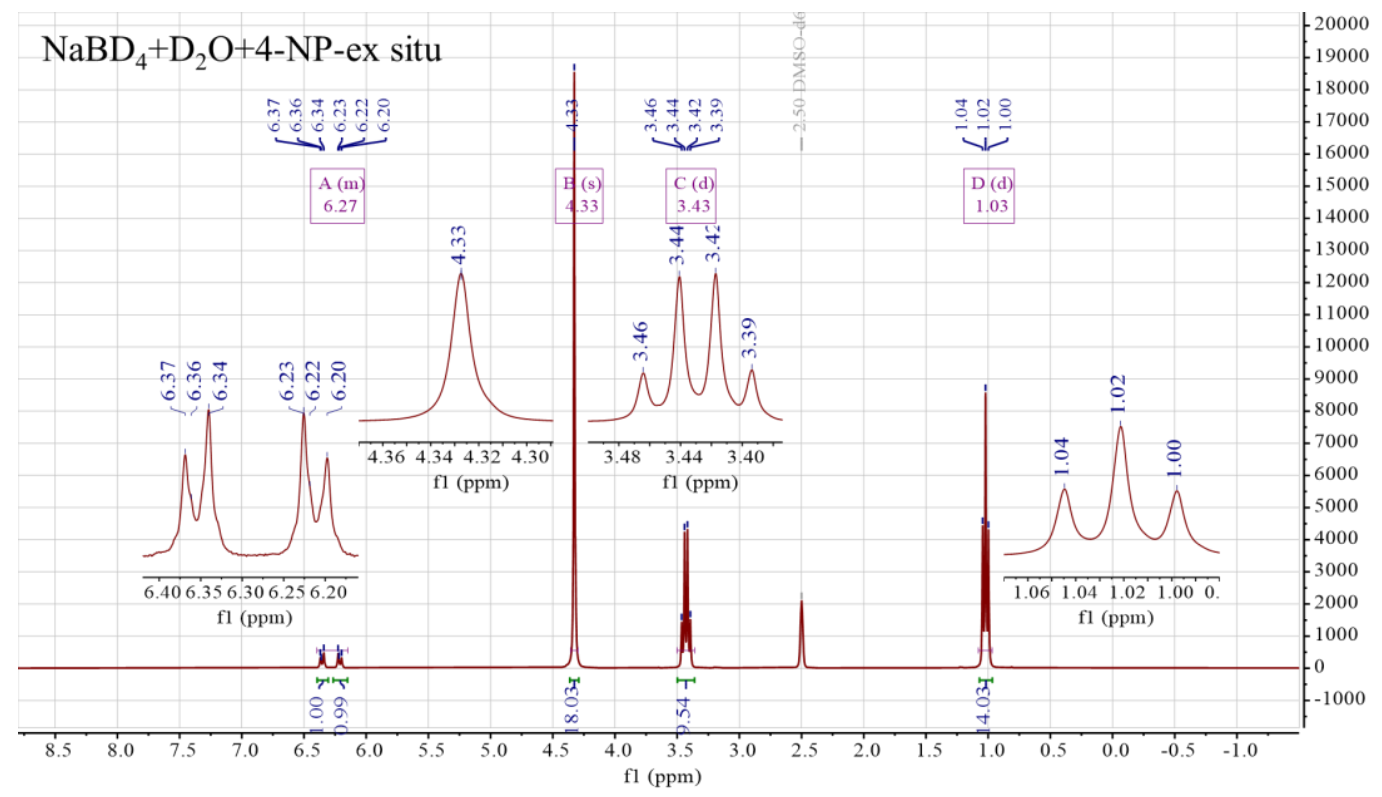

Figure S14. ${ }^{1} \mathrm{H}$ NMR spectrum of the reduction product using $\mathrm{NaBD}_{4}$ and $\mathrm{D}_{2} \mathrm{O}$ after the reaction. 


\section{Reference}

1. K. Zhang et al., Facile large-scale synthesis of monodisperse mesoporous silica nanospheres with tunable pore structure. J. Am. Chem. Soc. 135, 2427-2430 (2013).

2. X.-D. Hu, B.-Q. Shan, R. Tao, T.-Q. Yang, K. Zhang, Interfacial Hydroxyl Promotes the Reduction of 4-Nitrophenol by Ag-based Catalysts Confined in Dendritic Mesoporous Silica Nanospheres. J. Phys. Chem. C 125, 2446-2453 (2021).

3. H. Xiao-Dan, Y. Taiqun, S. Bingqian, P. Bo, Z. Kun, Topological Excitation of Singly Hydrated Hydroxide Complex in Confined Sub-Nanospace for Bright Color Emission and Heterogeneous Catalysis. ChemRxiv (2020).

4. Y. Zhao et al., Mechanistic Study of Catalytic Hydride Reduction of -NO2 to -NH2 Using Isotopic Solvent and Reducer: The Real Hydrogen Source. J. Phys. Chem. C 123, 15582-15588 (2019).

5. S. Liu, Y. Chen, L. Dong, Ag-Fe2O3nanocomposites with enhanced catalytic activity for reduction of 4-nitrophenol. Mater. Res. Express 3, 075024 (2016).

6. Y. Chi et al., Synthesis of Fe3O4@SiO2-Ag magnetic nanocomposite based on small-sized and highly dispersed silver nanoparticles for catalytic reduction of 4-nitrophenol. J. Colloid Interface Sci. 383, 96-102 (2012).

7. W. Li et al., Hollow mesoporous $\mathrm{SiO} 2$ sphere nanoarchitectures with encapsulated silver nanoparticles for catalytic reduction of 4-nitrophenol. Inorg. Chem. Front. 3, 663-670 (2016).

8. S. Lu et al., Preparation of silver nanoparticles/polydopamine functionalized polyacrylonitrile fiber paper and its catalytic activity for the reduction 4-nitrophenol. Appl. Surf. Sci. 411, 163-169 (2017).

9. L. Tzounis et al., Controlled growth of Ag nanoparticles decorated onto the surface of $\mathrm{SiO}_{2}$ spheres: a nanohybrid system with combined SERS and catalytic properties. RSC Adv. 4, 17846-17855 (2014).

10. C. S. Budi, J. R. Deka, D. Saikia, H.-M. Kao, Y.-C. Yang, Ultrafine bimetallic Ag-doped Ni nanoparticles embedded in cage-type mesoporous silica SBA-16 as superior catalysts for conversion of toxic nitroaromatic compounds. J. Hazard. Mater. 384, 121270 (2020).

11. Z.-S. Lv, X.-Y. Zhu, H.-B. Meng, J.-J. Feng, A.-J. Wang, One-pot synthesis of highly branched Pt@Ag core-shell nanoparticles as a recyclable catalyst with dramatically boosting the catalytic performance for 4-nitrophenol reduction. J. Colloid Interface Sci. 538, 349-356 (2019).

12. H.-T. Fan et al., Ordered mesoporous silica cubic particles decorated with silver nanoparticles: a highly active and recyclable heterogeneous catalyst for the reduction of 4-nitrophenol. Dalton Trans. 48, 2692-2700 (2019). 